\title{
ACCIONES LEGALES DE LOS RELIGIOSOS MARIANISTAS SOBRE SUS OBRAS COLEGIALES DURANTE LA SEGUNDA REPÚBLICA
}

\author{
POR \\ ANTONIO GASCÓN ARANDA, S. M. \\ Director del Archivo General Marianista de Roma
}

RESUMEN: Al advenimiento de la II República, los religiosos marianistas se encontraban firmemente implantados en España a través de obras escolares. Ante las leyes republicanas contrarias a la acción pública de las Congregaciones religiosas, los Marianistas se anticiparon a la legislación dando una identidad legal secular a sus establecimientos docentes. No obstante la enorme preocupación que ello generó entre los superiores, el acierto de esta estrategia se manifestó en el aumento del número de alumnos y de la cantidad de grados académicos de los religiosos.

PALABRAS CLAVE: Compañía de María (Marianistas); padre Domingo Lázaro; Ley de Confesiones y Congregaciones Religiosas; Federación de Amigos de la Enseñanza; Institución Libre de Enseñanza; Secularización.

\section{LEGAL ACTIONS OF THE MARIANIST RELIGIOUS REGARDING THEIR SCHOOL APOSTOLATES DURING THE YEARS OF THE SECOND REPUBLIC}

\begin{abstract}
At the beginning of the Second Republic, Marianist religious were already well established in Spain through their work in education. Before the Republican laws prohibited public works of religious congregations, the Marianists had anticipated such laws and made sure each of their educational establishments had a legal, civil identity. Despite the enormous concern that this generated among superiors, it is certain that this strategy led to an increase in the number of students and in the number of degrees for religious.
\end{abstract}

KEY WORDS: Society of Mary (Marianists); Fr. Domingo Lazaro; Law of Confessions and Religious Congregations; Federation of the Friends of Education; Free Institution of Instruction; Secularization

Recibido/Received 2011-07-17

Aceptado/Accepted 2011-10-24

En el año en que adviene la II República española, el Personal de la Provincia de España, de 1931-1932, de la Compañía de María (Marianistas) arrojaba una cifra total de 306 religiosos, distribuidos en 9 colegios de segunda enseñanza, 5 escuelas de primaria y 1 reformatorio (o Casa de Observación de Vitoria). Los religiosos estaban distribuidos: 231 en activo en las comunidades españolas; 5 en el Seminario marianista de Friburgo (Suiza); 41 universitarios en el Escolasticado superior (Segovia y Madrid); otros 13 escolásticos estudiantes de Magisterio y de Comercio y 8 
religiosos en el extranjero. El futuro se podía mirar con esperanza, dado que los novicios eran 16 y los postulantes se elevaban a 70 .

El padre Provincial, Gregorio Martínez de Murguía, residía en Madrid, junto con su asistente para las obras escolares - llamado Inspector- don Alonso Thibinger. Estos religiosos llevaban una vida serena y regular, tanto en sus tareas docentes cuanto en su vida religiosa. Pero, inesperadamente, con el advenimiento de la República la vida se hizo "extrañamente insegura" (Laín Entralgo) para todos ellos, como para el resto de los españoles. Así lo reflejaron en sus cartas personales e informes a los capítulos provinciales y a los Superiores mayores.

En efecto, "son tan agitados los días que atravesó España desde el 12 de abril de 1931 hasta el 18 de julio de 1936 que es imprescindible volver a cada paso sobre los acontecimientos políticos para situar y mejor explicar la vida y las actividades de los simples ciudadanos". ${ }^{1}$ Con estas palabras presenta los años republicanos el eximio marianista español don Antonio Martínez en su biografía del padre Domingo Lázaro, fundador de la FAE y una de las máximas figuras de la escuela católica durante la República.

Entre estos simples ciudadanos - de los que habla don Antonio- se encontraban los religiosos marianistas. En efecto, las obras y las vidas de los religiosos en España se vieron profundamente transformadas a raíz de la promulgación de los primeros decretos de Marcelino Domingo en el Ministerio de Instrucción; seguidos de la votación del famoso artículo 26 de la Constitución -noche del 13 al 14 de octubre de 1931-, de la disolución legal de la Compañía de Jesús -23 de enero de 1932-, la promulgación de la Ley de Confesiones y Congregaciones religiosas -2 de junio de 1933- y, finalmente, el triunfo electoral del Frente Popular en febrero del 1936.

En esta colaboración nos propones mostrar cómo afectaron las actuaciones político-legales de los gobiernos republicanos a las obras docentes de la Compañía de María en España. Proponemos esta congregación religiosa, que procedente de Francia había abierto en España su primera obra docente en 1887 en la ciudad de San Sebastián, como un caso típico del modo en el que las congregaciones intentaron adaptar sus obras escolares a la nueva legislación republicana en nuestro país. ${ }^{2}$

\section{EL LUGAR DE LA IGLESIA EN EL NUEVO ORDEN REPUBLICANO}

Damos por sabidos los acontecimientos políticos por los que el 14 de abril de 1931 fue proclamada la República. Nosotros nos centramos en la presentación del modo en que vivieron los Marianistas estos acontecimientos y cómo afectó la legislación del nuevo Estado a sus obras docentes.

Advirtamos que el advenimiento del nuevo régimen cogió por sorpresa a los religiosos marianistas, tanto como al conjunto del país. "Le escribo bajo el estupor que nos causa a todos el hecho insólito de encontrarnos en plena República (sic)", escribía el Provincial, padre Gregorio Martínez de Murguía, al Superior General, padre Ernesto Sorret, a los pocos días de declararse el nuevo régimen.

Siglas: AGMAR: Archivio Generale Marianista di Roma; APM: Archivo de la Provincia marianista de Madrid; APZ: Archivo de la Provincia marianista de Zaragoza; FAE: Federación de Amigos de la Enseñanza; SM: Societatis Mariae (Compañía de María, Marianistas).

1 Martínez, A. 1949. Un alma de educador. R. P. Domingo Lázaro Castro, SM (1877-1935): 258 Burgos: Hijos de Santiago Rodríguez.

2 Vid. "Los preocupantes años de la República", en Gascón, A. Compañía de María (Marianistas) en España. Una contribución al desarrollo y a la evangelización (1887-1983) I, (Madrid 2002) 567-641. 
"El resultado del escrutinio del domingo ha sido una sorpresa para todos. Los primeros sorprendidos han sido los republicanos". Pronto los altercados callejeros fueron motivo de sospecha y preocupación sobre las intenciones del nuevo sistema político. "¿Podrá este gobierno republicano detener a las hordas que vienen empujando? Por de pronto, iya en Barcelona y Bilbao han quedado proclamadas las repúblicas autónomas vasca y catalana (sic)! (...) Tenemos que prepararnos para cualquier eventualidad". "Estamos todos bajo la impresión penosa de una catástrofe que nadie podía suponer ni prever. (...) Estamos lejos de suponer que el descontento (de la Dictadura) fuese tan grande y profundo. (...) Pero el mal está hecho y Dios sabe hasta dónde caeremos en esta caída fatal. En el Consejo (provincial) todos somos pesimistas." El padre Gregorio reconoce que Alcalá Zamora y Martínez Barrio quieren una República de orden y respeto a la libertad y a la propiedad privada pero son demasiado débiles para contener a los socialistas y comunistas. Murguía teme que en las elecciones para las Constituyentes, republicanos y socialistas obtengan la mayoría ante la división de las derechas. "Entonces será preciso prepararnos para sufrir la más encarnizada persecución que jamás haya sufrido la Iglesia en España en todos los siglos de su historia." Pero estima "que no se debe hacer nada fuera de nuestra marcha habitual y continuar las clases y los exámenes".

Los gobernantes republicanos se enfrentaban a un cúmulo de problemas heredados; entre ellos, la educación. Eran altamente preocupantes las altas tasas de analfabetismo (el $33^{\prime} 73 \%$ de una población de veintitrés millones y medio de habitantes eran analfabetos y que un $60 \%$ de la juventud española carecía de enseñanza), el absentismo escolar, la falta de edificaciones escolares, el estado de abandono de la primera enseñanza, los sueldos indignos del profesorado... El gobierno provisional, por medio de su ministro de Instrucción Pública, Marcelino Domingo, emanó los primeros decretos para afrontar la solución de estos graves problemas y atajar el abandono de la primera enseñanza.

La Iglesia acogió con paz a la joven República. El Vaticano aceptó la situación de hecho; también los prelados, con mayor o menor dificultad interna. El Debate, con su editorial del 15 de abril, "Ante el poder constituido", acataba lealmente el primer Gobierno de la República, citando la doctrina León XIII exhortando a los católicos a participar en la vida política de las repúblicas liberales.

En el mismo sentido, el Secretario de Estado, Pacelli, pedía a obispos y católicos acatar el orden constituido y participar en el régimen democrático republicano apoyando la candidatura de derechas presentada por la coalición Acción Nacional para defender los derechos de la Iglesia y el orden social. En los mismos términos escribía el Superior general de la Compañía de María, padre Sorret, a los marianistas españoles en carta del 24 de junio de 1931 al Provincial Martínez de Murguía: "Veo con satisfacción que vuestro periódico El Debate ha tenido la buena idea de unirse al Gobierno y que numerosos Obispos han invitado a su clero a sostener igualmente el poder de hecho (...). Esta es la verdadera táctica: si todas las gentes de orden se uniesen entorno al poder, le facilitarían su pesada tarea y les ayudarán a mantener el orden". El Superior General terminaba invitando a los religiosos a la "confianza y abandono en la Buena Providencia", a la "abstención de toda ingerencia política (¡No portar armas!)", "estricta economía", "oración, penitencia, sacrificio" y "santidad de vida." En la misma línea de aceptar la situación de hecho se sitúan los religiosos marianistas, padre Florentino Fernández,

3 Carta del 15, IV, 1931 APM: 101.078, es fotocopia de AGMAR; la correspondencia del provincial español, Martínez de Murguía con el Superior general, Sorret, y demás miembros de la Administración general durante la República, en AGMAR: 076.5.1-252, en orden cronológico.

${ }^{4}$ Carta al Superior General del 26, IV, 1931 (APM: 101.083). 
padre Domingo Lázaro y el Provincial, quien escribe al Superior General, "à la guerre comme à la guerre" (algo así como "a mal tiempo, buena cara").

Al sobrevenir el nuevo régimen la institución eclesial era sociológicamente muy poderosa: el clero seguía siendo muy abundante y las organizaciones de apostolado numerosas; las congregaciones religiosas contaban con 4.804 casas, de las cuales 998 eran de varones y 3.806 de mujeres con sus obras docentes y de beneficencia. La Iglesia ejercía una gran influencia sobre todo, en la enseñanza, con 2.187 escuelas de primaria, 246 nocturnas y 250 profesionales, por cuyo medio marcaba fuertemente la ideología social. "En total, el censo de alumnos de las escuelas primarias regentadas por religiosos representaba la tercera parte de los que asistían a la enseñanza oficial. Respecto a la segunda enseñanza, mientras a los establecimientos oficiales asistían 25.000 alumnos, a los privados de los religiosos concurrían $27.000{ }^{\prime \prime}{ }^{6}$

Sin embargo, durante la redacción de la nueva Constitución los republicanos quisieron instaurar un Estado moderno no confesional. Pero, sujetos a los contenidos de una formación krausista y a su intención regeneracionista, poseían una interpretación negativa de la Iglesia en la historia de España. La Segunda República había heredado del sector intelectual del republicanismo burgués una política "asépticamente laica"; postura que Madariaga ha llamado "anticlericalismo punzante y constante"; en la línea de un laicismo hostil. A los diez días de proclamarse la República, el padre Domingo Lázaro, director del Colegio de El Pilar de Madrid, escribe en carta del 24 de abril al Inspector general de la Compañía de María, don Miguel Schleich, "anotaré algunas reflexiones concernientes a los acontecimientos recientes y las consecuencias posibles que se seguirán. (...) La República, implantada el día 14 de abril de 1936, fue fundada de hecho en 1876 por Francisco Giner de los Ríos y su Institución Libre de Enseñanza. Los buenos republicanos que han metido ruido estos días no son más que los maniquíes cuyos hilos mueven a voluntad la masonería, que desde hace cincuenta y cuatro años se ha ocupado de formar un personal docente inspirado en su espíritu laico y antirreligioso; ella se adueñó enteramente de las palancas de mando del Ministerio de Instrucción Pública, se ha filtrado en las Normales de ambos sexos y en la Universidad, sin que las gentes conservadoras (...) ni los Obispos se hayan enterado ni dado cuenta del peligro".

Entre tanto, el Gobierno provisional, ya desde el mes de mayo, va dictando unilateralmente disposiciones legales en orden a desmontar el precedente régimen confesional del Estado. Los obispos, reunidos en Toledo, el 9 de mayo formulan sus protestas por la impronta laicista del nuevo régimen. Pero el 11 de mayo en Madrid y el 12 en provincias ya se producen las primeras quemas de conventos. La lentitud del Gobierno en implantar el orden público frente a estos excesos provocó la desconfianza de los católicos. En tanto que los marianistas españoles seguían con preocupación los debates de la constituyente. El padre Provincial, Gregorio Martínez de Murguía, escribe al Secretario general de la Compañía de María, don Miguel García: "Por fin y no sin gran angustia, entramos en la semana más dura para las constituyentes; esta semana se van a tratar los temas: propiedad, familia, religión y

5 El P. Florentino Fernández en carta del 24, IV, 1931 al P. Provincial, Martínez de Murguía (APM: 101.082); y el Provincial, en carta del 5, IX, 1931 (APM: 101.099); carta del 24, VI, 1931 a Murguía: (APM: 101.081); Lázaro afirma: "Hacer, hacer mucho y callar”, en Atenas (octubre 1933).

6 Arrarás, J. 1970. Historia de la Segunda República española, II: 123 (n. 1) Madrid: Editora Nacional.

7 Martínez, A. 1949: 229-230. 
enseñanza. Cualquier cosa es de temer en estos jabalíes desatados. Estamos en manos de Dios, cúmplase su voluntad". ${ }^{8}$

En efecto, el debate del artículo 24 del proyecto constitucional (26 definitivo) sobre la supresión de las órdenes religiosas comportó la primera crisis política de la República. Azaña salvó la existencia de las congregaciones, a cambio de la disolución legal de la Compañía de Jesús y de prohibir a las congregaciones la docencia y el ejercicio de actividades industriales y comerciales. De este modo, la República terminó por atraerse las suspicacias y temores de los católicos, rompiendo el consenso republicano de los ministros de derechas. "La imprudencia de esta medida resulta hoy evidente", afirma Brenan; Jerarquía y congregaciones religiosas vieron en estas leyes una República animada de sentimientos laicistas y anticlericales. El padre Martínez de Murguía enjuicia los acontecimiento y anticipa las consecuencias políticas: "el Gobierno ha arrojado por la borda a los católicos y conservadores -Alcalá Zamora y Miguel Maura- haciendo de este lastre una marcha a pasos agigantados hacia el abismo."

Conocida la votación del artículo 26, el mismo día 14 de octubre escribe el Provincial al Superior general Sorret dándole fiel noticia de la situación en la que va a quedar la Compañía de María, "prácticamente, (se) nos impide continuar nuestra hermosa labor religiosa en España"; si bien cabe la esperanza que el artículo no se llegue a aplicar o no se haga de manera inmediata y rigurosa por falta de financiación estatal. La Constitución así elaborada "es ultrarradical y no podrá ser aplicada en una marcha normal"; además, ponía fuera de la ley a los religiosos.

En su Informe al Capítulo Provincial de 1 a 3 de enero de 1932, convocado en Madrid inmediatamente después de la votación de la Constitución y los sucesos de la quema de conventos, el padre Martínez de Murguía deja traslucir su honda preocupación ante la situación política y social que está viviendo el país; y las consecuencias de la legislación republicana sobre las obras docentes de los Marianistas. En primer lugar, el Provincial señala un fenómeno común a toda la sociedad española, que es el contraste entre la ilusión con que se esperó el advenimiento de la República y la conflictividad política y social que ha sobrevenido. En este ambiente los religiosos viven con intranquilidad y hasta con miedo los insultos y agresiones verbales que reciben y que les hace ir creando una mentalidad incipiente de persecución religiosa. "Nunca nos hemos reunido en circunstancias tan graves como las que nos rodean hoy. A la paz y sosiego de estos últimos años ha seguido una época turbulenta, en la que todo se agita, por efecto del vendaval desencadenado por el infierno contra la Iglesia de Cristo. (...) Vino, luego el ataque solapado, pero dañino exigiendo título oficial para enseñar, decreto que si se hubiese podido llevar a la práctica hubiera sido la muerte de casi todas las Ordenes dedicadas a la enseñanza (...). Por fin vino el golpe de muerte en el artículo 26 de la Constitución impuesta por la tiranía socialista por el que se prohíbe la enseñanza, la industria y el comercio a los religiosos." ${ }^{12}$

\footnotetext{
${ }^{8}$ Carta del 6, X, 1931 (APM: 101.103).

9

Brenan, G. 1994. El laberinto español: 261 Madrid: Globus.

${ }_{11}^{10}$ Repetidas manifestaciones al Superior General: carta del 22, X, 1931 (APM: 101.105).

${ }^{11}$ Carta del 14, X, 1931 (APM: 101.104); del 29, X, 1931 (APM: 101.106) y 10, XII, 1931 (APM: 101.112).

Congregatio de Causis Sanctorum (Torres, E.). 1990. "Disquisitio super martyrio", en Civitatis Regalen.Canonizationis seu declarationis martyrii servorum Dei Caroli Eraña Guruceta et duorum sociorum (...) anno 1936, interfectorum. Positio super martirio: 11-14 Roma: Tipografia Guerra.
} 
Los obispos españoles también hablaron en aquellos días. Aprobada la Constitución el 9 de diciembre de 1931, el primer día del nuevo año 1932 la Jerarquía daba a conocer una pastoral colectiva en la que rechazaban la nueva Constitución en aquellos puntos contrarios a la doctrina católica y al Estado confesional. Por lo que respecta a la educación la posición del episcopado es clara y terminante: la educación está basada en la ley natural; es anterior y superior a las leyes del Estado y el derecho asiste a los padres a elegir la educación de sus hijos en conformidad con sus creencias. Se recuerda el derecho divino del que goza la Iglesia para venir a la educación y formación cristiana de sus fieles por medio de escuelas propias y aún en las públicas. En consecuencia se insta a los católicos a que impidan la ascensión del laicismo "oponiéndose a los avances de la escuela laica, obra del Estado", la cual acaba por convertirse, a despecho de sus defensores, de neutra en atea y se hace fuente de descristianización de las conciencias infantiles. Los Marianistas españoles se adhirieron a esta doctrina.

Por los trabajos de la profesora Mercedes Samaniego sabemos que todas las corrientes pedagógicas del momento -sobre todo, institucionistas y socialistas- llegaron a los gobernantes republicanos en el Ministerio de Instrucción, menos el reformismo educativo de inspiración cristiana. Más aún, que el articulado de la Constitución referente a la enseñanza fue completado por la Ley de Confesiones y Congregaciones religiosas, de 2 de junio de 1933, suprimió la enseñanza confesional. ${ }^{13}$ Los hombres y los ministros al frente del Ministerio de Instrucción Pública -Marcelino Domingo, Fernando de los Ríos, Manuel Bartolomé Cossío, Luis Zulueta, Álvaro de Albornoz, Jiménez de Asúa, Julián Besteiro y Filiberto Villalobos- eran republicanos y socialistas. Ante los múltiples problemas heredados para la modernización de España, piensan que "la solución de los problemas es solamente cuestión intelectual, de dinámica gobernante. Lo esencial es educar... El problema de España es un problema político, cultural." De aquí la determinación de los nuevos gobernantes por dominar la organización escolar española.

¿Cómo reaccionaron los religiosos marianistas ante la legislación escolar republicana? Sus iniciativas se movieron en diversas direcciones: apoyar las iniciativas católicas, sobre todo de la FAE; anticiparse a los acontecimientos para acomodarse a la legislación; dar a los religioso un estado de secularización fingida; establecer vías de escape con nuevas fundaciones -caso de llegarse a la expulsión de las obras propias- $\mathrm{y}$, un vez votada la Ley de Confesiones y Congregaciones, se procedió a la trasformación legal de las obras escolares propiedad de la Compañía de María.

\section{APOYO A LAS INICIATIVAS CATÓLICAS: LA FEDERACIÓN DE AMIGOS DE LA ENSEÑANZA}

En primer lugar, los religiosos marianistas se mostraran diligentes en la defensa de los intereses educativos de la enseñanza confesional; sobre todo a través de la FAE (Federación de Amigos de la Enseñanza), en cuya fundación había estado activamente presente el sacerdote marianista Domingo

${ }^{13}$ Samaniego, M. 1977. La política educativa de la Segunda República durante el bienio azañista: Madrid: CSIC: 36

14 Alba, V. 1961. Historia de la Segunda República española: 124-125 México: libro Mex; "de este modo, el programa básico de la República quedaba idealmente trazado con esas palabras de la Gaceta: "Ha llegado el momento de redimir a España por la escuela.", en Puelles, M. 1980. Educación e ideología en la España contemporánea: 320 Barcelona: Labor; Sobre el ministro Fernando de los Ríos Urruti, sobrino de Francisco Giner de los Ríos, catedrático de Derecho, profesor de la Institución Libre de Enseñanza y afíliado al Partido Socialista, liberal y demócrata de centro-izquierda de talante reformista y europeo el P. Martínez de Murguía afirma que "sin ser un sectario rabioso es un hombre de partido muy avanzado y que siempre ha figurado en el cartel de los enemigos de la Iglesia.", carta al Superior General del 13, XII, 1932 (APM: 101.198). 
Lázaro. El padre Lázaro pertenecía a la Junta Directiva, junto con el sacerdote diocesano Pedro Poveda y el jesuita Enrique Herrera. A la FAE le tocará actuar intensamente durante los años de la Segunda República, multiplicando sus esfuerzos y convirtiéndose en el contrapunto de la acción legal del Gobierno en materia de enseñanza. Para ello creó el Instituto Pedagógico, organizó las Semanas de Estudios Pedagógicos y manifestó el pensamiento escolar católico a través de la revista Atenas. Al frente de estas iniciativas encontramos al padre Domingo Lázaro. ${ }^{15}$ Lógicamente, el padre Domingo pidió colaboración a prestigiosos profesores marianistas del colegio de Nuestra Señora de el Pilar de Madrid. La actividad más notable del padre Domingo fue la dirección de Atenas. Revista de información y orientación pedagógica (cuyo primer número había aparecido el 15 de abril de 1930), órgano de información y orientación pedagógica, de carácter profesional y de opinión, que fue el logro más interesante de la FAE.

\section{ANTICIPARSE A LOS ACONTECIMIENTOS Y ACOMODARSE A LA LEGISLACIÓN}

El padre Gregorio Martínez de Murguía estuvo al frente de la Provincia marianista de España durante el período de las Constituyentes y del bienio reformista, hasta octubre de 1934. Fueron los años en que los nuevos gobernantes llevaron a la práctica una legislación reformista en materia educativa. Legislación que terminó con la prohibición de la docencia a las Congregaciones religiosas, por la Ley de Confesiones del 17 de mayo de 1933. La estrategia del padre Martínez de Murguía y de sus consejeros consistió en anticiparse a la legislación mediante la acomodación de los colegios y de los religiosos a la situación legal, otorgándoles una apariencia externa secularizada.

Ante tan graves actuaciones legales, los Marianistas temieron que se repetiría en España la legislación de los radicales de la III República francesa contra las congregaciones docentes. Esta preocupación aparece manifiesta en el informe del padre Martínez de Murguía al Capítulo celebrado del 2 al 3 de enero de 1933, donde declara que "vivimos en plena persecución religiosa. La táctica que siguen nuestros gobernantes parece calcada en la que siguieron en Francia en 1903". El Provincial teme sobre todo ser expulsados de la enseñanza y de España.

El detonante de todos los miedos vino antes por la vía de los hechos, que por la legislación republicana. Ya a partir de la quema de conventos e iglesias en Madrid el 31 de mayo de 1931, el estado mental de los religiosos fue de pena y preocupación. Los superiores tomaron, entonces, las primeras precauciones: vestir de paisano a los religiosos y lanzarlos a la calle para vigilar los alrededores del colegio de El Pilar, sito en el barrio de Salamanca. Se les dio 50 pesetas y se les asignó algunas familias amigas donde pudieran hospedarse. Del Colegio se sacaron los objetos de más valor y

15

Labrador, C. 1985. "Las Semanas de Estudios pedagógicos de la FAE (1932-36)", en Ruiz Berrio, J. (ed.), La educación en la España contemporánea. Cuestiones históricas: 242-252 Madrid: Sociedad Española de Pedagogía; Bartolomé Martínez, B. y Hernández, J. 1985. "La Federación de Amigos de la Enseñanza (FAE) como alternativa pedagógica", en Ibidem: 255-261; Labrador, C. 1994. "Federación de Amigos de la Enseñanza", en Delgado, B. (coord.), Historia de la Educación en España y América, III: 823-826 Madrid: ed. SM y ed. Morata; la causa de beatificación del padre Domingo Lázaro fue introducida en la archidiócesis de Madrid (septiembre de 1988 a diciembre de 1995) y la Positio fue presentada en la Congregación para las Causas de los Santos en mayo de 2002; biografía actualizada por Salaverri, J. M. 2003. Domingo Lázaro (1877-1935). Un educador entre dos grandes crisis de España: Madrid: PPC.

${ }^{16}$ Martínez de Murguía, Memoria al $31^{\circ}$ Capítulo Provincial, Archivo General Marianista (AGMAR: 074.3.7). 
se depositaron en casas de familiares y amigos. ${ }^{17}$ Desde entonces, los religiosos vivieron intranquilos y pendientes de los acontecimientos.

Las primeras medidas legislativas del Gobierno provisional, antes de la formación de la Asamblea constituyente, forzaron a adecuarse a las nuevas disposiciones legales. Los decretos del ministro Marcelino Domingo, del 21 de mayo y de 25 de agosto de 1931, prohibiendo el ejercicio docente en la primera y segunda enseñanza a todas aquellas personas que carecieran del título necesario, se convirtió en un grave obstáculo para los religiosos jóvenes, que en la tradición marianista compaginaban los estudios universitarios con el trabajo docente; y también para aquellos religiosos que a pesar de las insistencias de los Superiores aun no habían conseguido obtener sus grados académicos.

Es claro que esta legislación tuvo sus efectos positivos sobre la preparación académica de los profesores marianistas. El Consejo provincial mandó crear comunidades formadas por ocho o diez religiosos estudiantes, situadas en pisos de vecinos cercanos a la Universidad Central. Los religiosos se matriculan de alumnos oficiales y asisten a las aulas siguiendo el curso universitario vestidos con traje de color. Entre los años 1931 y 1934 se abrieron Casas de Estudios en pisos de vecinos cercanos a la Universidad Central: en Beneficencia, 2, luego trasladada a San Bernardo y en Benito Gutiérrez, 47, cercana a la Ciudad Universitaria; este piso de estudiantes fue trasladado a Zaragoza en noviembre de 1933, a un piso de la calle Miguel Servet, 17, que se cerró en septiembre de 1934 porque era muy costoso mantener abiertas tantas casas de formación. Entonces los religiosos universitarios fueron concentrados en el Escolasticado de Segovia y en la Residencia Provincial, sita en el colegio de El Pilar de Madrid.

La fórmula se reveló muy satisfactoria; y en el informe del Inspector de las escuelas marianistas al Capítulo Provincial del 1 y 2 enero de 1932, se hace un balance muy favorable de la situación y se congratula de los resultados obtenidos. Estas mejoras de la capacitación profesional e intelectual hicieran exclamar con ironía al señor Inspector, don Alonso Thibinger, que se las "debemos a un Ministro nada adicto a nuestras creencias. Si supiera nuestro enemigo el bien que nos hace, dejaría de hacer a las Congregaciones el blanco de su persecución"; y "lo que puede hacer la palabra de un Ministro, ni un Provincial ni el Inspector son capaces".

\section{MEDIDAS DE SECULARIZACIÓN FINGIDA}

${ }^{17}$ Carta del P. Murguía del 12, V, 1931, al Superior General (APM: 101.087). También en Cádiz el 14 de mayo las masas ocuparon las calles y asaltaron edificios religiosos, de los cuales sólo respetaron San Felipe Neri y el colegio de los Hermanos de las Escuelas Cristianas; cfr. Murguía, 14, V, 1931, al P. Sorret (APM: 101.088).

Carta de Murguía a Sorret, 25, VI, 1931 (APM: 101. 094) da cuenta del buen efecto entre los religiosos que "ponen mucho interés en estudiar" para obtener diplomas oficiales y licencias universitarias; el mismo asunto en carta 16, VII, 1931 (APM: 101.095).

${ }^{19}$ Casas citadas en la solicitud de inscripción n 4080 para el reconocimiento legal de la Compañía en el Ministerio de Justicia, con fecha del 19, IX, 1933; Martínez. A. 1949: 233-234; Martínez, J. 1980. Un renovador de la docencia nacional. D. Antonio Martínez García, Religioso Marianista. Fundador de Ediciones SM: 133 Madrid: ed SM.

${ }^{20}$ Carta de D. Alonso al Superior General, Tetuán, 11, XI, 1931 (APM: 101.107); $30^{\circ}$ Capítulo Provincial de España, 1-2, I, 1932, en APM. 
A tenor de la legislación y del cariz que van tomando los acontecimientos políticos, en el verano de 1931 los superiores comenzaron a dictar las primeras medidas de secularización externa para ocultarse a las miras de las acciones anticlericales y en previsión de la posible supresión de todas las congregaciones: los religiosos son cambiados de colegio y ciudad para adecuarse a la ley del 25 de agosto y contar así con cinco licenciados por claustro.

La disolución legal de los Jesuitas el 23 de enero de 1932, al mes de ser votada la Constitución, hizo temer por la permanencia en las propias obras educativas. El Consejo Provincial adelantó las primeras medidas de secularización en Madrid por temor a que el Colegio del Pilar fuera incautado para Instituto. Entonces pensó que, con la ayuda de personas amigas, se podrían abrir nuevos colegios en barrios próximos donde situar a los religioso en caso de una expropiación forzada del colegio de El Pilar. Con esta finalidad y asesorados por don Pío García Escudero, don César de la Mora, don Antonio Besagoiti, don Baltasar Márquez y don Aquiles Ullrich, personas competentes y de confianza, la Administración Provincial y la dirección del Colegio decidieron crear una sociedad anónima escolar. Los estatutos de la sociedad fueron redactados por don Ricardo de la Cierva. La Administración General marianista aceptó tal determinación y, así, el 17 de febrero de 1932, ante el notario y con padres de familia del colegio del Pilar como personas interpuestas, se dio de alta la fundación "Sociedad Anónima Cultura y Educación" (CESA), que "tiene por objeto la explotación mercantil de la industria de la enseñanza primaria, secundaria, especial y superior, tanto general como técnica, con arreglo a las Leyes". ${ }^{21}$ Seguidamente, Cultura y Educación alquiló un piso en el número 23, $1^{\circ}$, de la calle Juan de Mena, donde estableció un pequeño colegio legalmente reconocido, de primera y segunda enseñanza, llamado "Atenas", que comenzó con diecisiete alumnos. Propietario legal figuraba don Pío García Escudero y el Director Técnico era don Tomás Mora Mateos (propagandista y abogado); las clases eran impartidas por cinco marianistas y una señorita estaba al frente de los parvulitos. La CESA recibió su reconocimiento legal en el siguiente mes de marzo y en el capital fundacional participaba la Compañía de María con 55.000 pesetas.

El miedo a la disolución legal extremó las medidas de precaución. El Superior general, padre Ernesto Sorret, otorgó por carta del 19 de octubre de 1932 al padre Martínez de Murguía la concesión de poderes discrecionales, que en caso de necesidad preveían las Constituciones, art. 457, para actuar en cada obra sin consultar a la Administración General cuando faltare el tiempo necesario para tomar una decisión urgente. En su Circular del 22 de enero de 1932 el padre Sorret comunicaba a la Compañía "las pruebas de la Provincia de España". Afirmaba que "un viento de persecución sopla, desde hace un año, sobre la Iglesia de España". Pero en medio de tanta dificultad los colegios marianistas no han perdido alumnos porque las familias católicas no dejan de enviar sus hijos a los colegios religiosos. El General teme la expulsión de los marianistas de España, pero recordando el consejo de Pío XI, recomienda "esperar" porque esta situación se debe a la ignorancia y a la maldad de los hombres. Porque "Dios es el soberano de los acontecimientos; él los ordena y dirige según su voluntad y los orienta a buen fin. (...) ¡Tengamos confianza! Nuestra Madre del Cielo, a quien la Compañía pertenece, cuida de esta porción de la obra que ella misma ha inspirado en la tierra de

${ }^{21}$ Estatutos de "Cultura y Educación S. A.", en APM: caja Juan de Mena; solicitud, del 15, IX, 1932, al Sr. Rector de la Universidad de Madrid para incorporarse al Instituto Cervantes.

${ }^{22}$ Carta de Murguía a D. Miguel García, 13, I, 1934 (APM: 101.169); Murguía a la Administración General., 12, XI, 1932; cfr. Gordejuela, Anales de la Provincia de España, 41, en APM; Martínez, A. 1949. Un alma de educador: 233 Burgos; González Blasco, P e Isasa, J. 2007. "El nuevo colegio (1921-1936)", en El Pilar, cien años de historia. 1907-2007: Madrid Colegio Nuestra Señora del Pilar. 
España a su servidor, el padre Chaminade." El padre Sorret revela que "la persecución ha despertado en los religiosos el espíritu de fe". Este espíritu se contagia al resto de la Compañía que muestra su apoyo a los hermanos españoles.

Los miembros de la Administración General -padre Sorret, padre Lebon, el Secretario don Miguel García y el Inspector don Miguel Schleich- visitaron España para conocer sobre el terreno la situación religiosa y escolar. Tras la visita, con la circular de 29 de diciembre de 1932, Sorret felicitaba a los marianistas españoles por el testimonio de "renovación del espíritu de piedad, espíritu de sacrificio, de fidelidad a la Regla, de espíritu de familia que se manifiesta en vosotros." Les anima a no ceder a la inquietud, al temor o al desánimo.

\section{FUNDAR EN ARGENTINA, VÍA DE ESCAPE E IMPULSO MISIONERO}

Otra medida para salvarse de las medidas legales contra las congregaciones docentes fue la de fundar obras fuera de España. El recuerdo de los marianistas expulsados de Francia en 1903, condujo al Consejo Provincial a ensayar vías de salida a lugares de nueva implantación en caso de una expulsión o de una asfixia legal que hiciera inviable la enseñanza en España. Estas medidas dieron como resultado la fundación en Argentina. El Consejo consideraba que era conveniente "abrir una puerta al exceso de personal, dado que en este momento no podemos soñar con abrir casas nuevas en España y además es prudente tener una puerta abierta en el caso de una disolución. Además el Buen Padre (Superior General) nos exhorta a tener un país de misión para sostener el fervor misionero de nuestros jóvenes".

El padre Gregorio Martínez de Murguía y sus consejeros procedieron a buscar un explorador y se fijaron en don Pedro Martínez Saralegui, quien aceptó de buen grado. ${ }^{24}$ Por sus dotes intelectuales y su don de gentes, don Pedro fue el hombre apropiado para llevar adelante con éxito esta misión. Don Pedro era profesor en el colegio de El Pilar de Madrid, donde se reveló un pionero de la psicología aplicada a la educación. Licenciado en Filosofía por la Universidad de Madrid, era un ponente habitual en las Semanas de Estudio Pedagógico de la FAE. Muy interesado en las nuevas corrientes pedagógicas, en 1929 había realizado un viaje de estudios por diversos institutos educativos de Europa.

${ }^{23}$ Cartas de Murguía al P. Sorret del 6, VI, 1932 (APM: 101.148); 29, X, 1931 (APM: 101.106) y 25, I, 1932 (APM: 101.127).

${ }^{24}$ Intercambio epistolar entre Murguía y el Superior General durante el año 1932, con motivo de la fundación de Argentina: 6 y 18, de junio (APM: 101.148 y 101.149), 3 y 16 de julio (APM: 101.152 y 101.156); una carta de Pedro Martínez Saralegui del 21, IX, 1932 al P. Sorret (APM: 101.161); L'Apôtre de Marie 250: $146-147$.

${ }^{25}$ Dossier en AGMAR: Martínez Saralegui Pedro; son numeroso los libros escolares y de psicología de don Pedro, entre los que destacaron: 1942. El ideal, la conquista del carácter, el corazón: Madrid: ed. Fax; 1918. Biblioteca la leyenda blanca: Madrid: Nueva librería católica; 1924. Madre España. Libro de lectura. Grado medio y superior: Madrid: Hijos de Benigno Ayora; y 1923. Los tres hermanitos de "La Talanquera". Lectura: Madrid: Hijos de Benigno Ayora, todos con numerosas reediciones; biografía de don Pedro y su obra pedagógica por Tocalini, A. 2010. El legado de don Pedro: Buenos Aires: Familia Marianista de Argentina. 
No nos ocupamos aquí de la fundación en Argentina; ${ }^{26}$ nos baste saber que don Pedro partió del puerto de Cádiz el 16 de julio de 1932 y que dada la escasez de recursos económicos, el Consejo Provincial decidió que no se debía fundar un colegio propio, sino acoger la dirección de una escuela ya creada. Fue así como don Pedro, a indicación del señor Arzobispo de Buenos Aires, recibió de doña Juana Rita de Oromí -Presidenta de la Sociedad Escuelas Argentinas Gratuitas, perteneciente a la "Obra de la Conservación de la Fe"- la dirección de la escuelita de primera enseñanza "General Benito Nazar", para hijos de emigrantes, sita en el barrio de las Flores, calle Río de Janeiro, n 1.771 .27

La urgencia con la que se quiere establecer la cabeza de puente en América se denota por la prontitud con que se formó la comunidad destinada a dirigir esta escuela popular; los religiosos se embarcaron el 11 de diciembre de 1932. Homologaron sus títulos españoles en Argentina y el 6 de marzo de 1933 comenzaron las clases con 470 alumnos.

\section{LEY DE CONFESIONES Y TRANSFORMACIÓN LEGAL DE LOS COLEGIOS}

Finalmente llegamos al mayor problema creado por la II República a los colegios de titularidad marianista en España: la Ley de Confesiones y Congregaciones religiosas.

El 14 de octubre, al comenzar el curso 1932-1933, el ministro de Justicia, Albornoz, presentaba en el Congreso el proyecto de Ley de Congregaciones; con la discusión de la ley vuelven los temores para los religiosos. Se disipaba así la ilusión de que las legislaturas sucesivas no sacasen del texto constitucional unas consecuencias tan exigentes para la Iglesia, pues a partir de la ley de Congregaciones se materializaba la expulsión de los religiosos de la enseñanza.

El 17 de mayo de 1933, por el drástico procedimiento de la "guillotina", era votada "la ley más odiosamente anticlerical de toda Europa durante el siglo XX". ${ }^{28}$ En lo que afectaba a la tarea docente de la Compañía de María, resultaba nefasto todo lo referente a las actividades económicas (art,s. 27 a 29) y a la enseñanza (art. 30): las Congregaciones no podían poseer más bienes que los necesarios para vivienda y fines privativos; no pudiendo ejercer comercio, industria, ni explotación agrícola -salvo los productos destinados a la propia subsistencia-. No podrán dedicarse al ejercicio de la enseñanza, ni crear o sostener Colegios, ni directamente ni valiéndose de personas seglares interpuestas. En el plazo de un año, los religiosos debían cesar en el ejercicio de toda explotación económica y para la

26 Anonimo. 1946."La Compañía de María en la Argentina". El Pilar. Órgano de los colegios marianistas de España 44: 10-11; Andrés, M. (dir.). 1985. 50 años. Colegio Marianista. Bodas de oro: Buenos Aires: Savini Hnos. S.R.L..

${ }^{27}$ Las asociación de señoras católicas denominada "Obra de la Conservación de la Fe", fue fundada en 1901 por Mns. Espinosa, obispo de Buenos Aires para combatir los efectos de otra institución parecida de confesión protestante "o por mejor decir, anticatólica", en los barrios más abandonados de la Capital, compuestos por población heterogénea de inmigrantes. La Obra, protegida por el Estado, tuvo un importante desarrollo hasta 1930. Cuando los marianistas se hicieron cargo de la Escuela $n^{\circ} 11$, la Obra contaba con un total de 12 escuelastaller, 1 de enfermeras, 12 talleres de corte y confección, bordado y planchado, 3 academias de corte y confección y 1 curso de comercio; solamente la Escuela Gral. Benito Nazar era masculina, cfr. Juana Rita Villate de Oromi, Memoria de la Asociación Escuelas Argentinas Gratuitas "Obra de la Conservación de la Fe". Fundada en el año 1901, año 1934-1936, en APM: Datos relacionados con la fundación e historia de los marianistas en Argentina (Buenos Aires) 1932-1948; L'Apôtre de Marie 259: 104-105; Ibidem 266: 386-390; Martínez, A. 1946. "La Compañia de María en Argentina". El Pilar 44: 11-12; Ibidem 45: 9-12.

${ }^{28}$ Jarlot, G. 1984. "Guerra Mundial y Estados Totalitarios", en Historia de la Iglesia Fliche-Martin, XXVI/2: 335. Valencia: Edicep.

Hispania Sacra, LXIV, Extra I, enero-junio 2012, 149-177, e-ISSN: 1988-4265, doi: 10.3989/hs.2012.028 
enseñanza este plazo "cesará el primero de octubre próximo para toda clase de enseñanzas, excepto la primaria, que terminará el 31 de diciembre inmediato" (art. 31, a y b).

Como era de esperar, el episcopado respondió inmediatamente con una pastoral colectiva hecha pública el 2 de junio, el mismo día que la Gaceta recogía la nueva disposición legal. La Pastoral se refería a la Ley como "odiosa tiranía del Estado" para "poner límites a la función docente de la Iglesia". El episcopado enseñaba que compete a los padres, por derecho natural, elegir la educación de sus hijos en conformidad con sus propias creencias, y la Iglesia por derecho divino es garante de la educación cristiana de sus hijos en escuelas propias y aun en las públicas. La pastoral obligaba terminantemente a los padres católicos a mandar a sus hijos únicamente a las escuelas católicas. Los obispos prohíben a los fieles la asistencia a las escuelas acatólicas, neutras o mixtas, correspondiendo al Ordinario autorizar la asistencia a las mismas en determinadas circunstancias; y si esto es así, los padres han de vigilar los textos escolares, estimular la fe cristiana de los hijos y apartarlos "del trato de amistad con los compañeros escolares que puedan poner en peligro su fe y costumbres cristianas."

Era una verdadera "guerra escolar", principio de desafecto e irreconciliación entre los católicos y la República. La acción de los obispos fue apoyada por el Papa en su encíclica Dilectissima Nobis, del 3 de junio. ${ }^{29}$ Se duele el Romano Pontífice que la Ley "constituye una nueva y más grave ofensa, no sólo a la religión y a la Iglesia, sino también a los decantados principios de libertad civil, sobre los cuales declara basarse el nuevo régimen español (...). Por consiguiente, Nos protestamos solemnemente y con todas nuestras fuerzas contra la misma ley."

Una vez más, la voz del padre Domingo Lázaro se convierte en faro y guía del pensar y sentir de los religiosos marianistas. Lázaro dedicó un suelto en la revista Atenas de junio de 1933 titulado, "¡CONSUMATUM EST!". "La Ley, la funesta y malhadada Ley -la Loi du malheur-, se aprobó. Ocurrió, pues lo que tenía que ocurrir" (...). La finalidad es patente: descristianizar y paganizar a España, descristianizando y paganizando a la infancia y a la adolescencia. (...) "Advirtamos que lo único importante para nuestros enemigos en esta Ley es lo referente a la enseñanza". EL padre Lázaro evidencia al final el argumento de fondo en la polémica: "Dicen que los religiosos educadores son el 'peor enemigo'."

Durante la discusión parlamentaria de la Ley, la Administración Provincial procedió a realizar consultas a personas amigas, al mismo tiempo que previendo la secularización plena de la Compañía de María-Provincia de España, la Administración General extendió a los religiosos un documento oficial de secularización. Se llega al extremo de consultar al ministro Fernando de los Ríos, quien dijo "que él no veía inconveniente en que los Marianistas tuviesen títulos y estando secularizados continuasen enseñando en los colegios transformados en sociedades anónimas".

Los días 21 y 22 de junio se reunieron en Madrid los directores de los colegios marianistas para exponer la situación de cada casa. "Todos están convencidos que seremos ejecutados sin piedad y nos

${ }^{29}$ Gutiérrez, J. L. y Martín-Artajo, A. 1958. Doctrina Pontificia. Documentos políticos, II, BAC, nº 174, 622-641; Puelles, M. 1980: 335-336.

${ }^{30}$ Contestación de la Admón. Gral., del 12, VI, 1933 con todas las precauciones a tomar, en APM: 101.236. La cédula personal de exclaustración extendida por el Superior General a cada religioso, en Antonio Martínez, Los marianistas y la Cruzada Nacional (21, VI, 1941, Zaragoza) (mecanografiado, 181 pág,s.), 29, en APM; cartas del P. Murguía al Superior Gral., de noviembre de 1932, en APM: 101.190; otra del 13, XII, 1932 (APM: 101.198), y a D. Miguel Schleich del 6, XII, 1932 (APM: 101.196). 
preparamos para defender nuestras obras". Se decidió no ceder un palmo; resistencia activa. De momento la ley autorizaba la enseñanza primaria, por lo que hasta agosto se podía continuar en los locales actuales. La respuesta de la Administración General marianista a esta reunión fue taxativa: aceptaba toda solución menos vender los edificios. En consecuencia, el día 22 de octubre de 1933 se presentaron los documentos para pedir el reconocimiento legal de la Compañía de María; ${ }^{31}$ transcurrido el verano de 1933, al comenzar el nuevo curso escolar los religiosos ya habían transformado la propiedad de sus colegios en sociedades anónimas para acomodarse a la ley; en común estrategia con todas las Congregaciones religiosas y asociaciones católicas.

No se tomó ninguna medida especial con las casas de formación (postulantado de Escoriaza, noviciado de Elorrio y Escolasticado de Segovia) porque la Ley respetaba la propiedad y usufructo de tales establecimientos destinados a vivienda de los religiosos. Tampoco se precisaba adaptar las escuelas gratuitas y Fundaciones de los Colegio Ntra. Sra. del Carmen en El Royo (Soria), Instituto Popular de Concepción en Ciudad Real, la escuela municipal de Elgoibar (Guipúzcoa), la Casa de Observación y Detención, dependiente del Tribunal Tutelar de Menores, de Vitoria, el Colegio de Ntra. Sra. de la Asunción, en Yurre (Vizcaya), por no ser propiedades de la Compañía. Tampoco lo eran las escuelas del Santísimo Cristo de Villarrín (Zamora) y el Colegio San José de Suances (Santander). Respecto a la escuela de Villarrín, el Patrono del establecimiento, propiedad de la Diócesis de Astorga, la trasformó en escuela parroquial y firmó un nuevo contrato laboral con cada uno de los religiosos. En cuanto a la escuela de Suances, la descapitalización de la Fundación obligó al Patronato a establecer un nuevo contrato con la Compañía de María.

En el verano de 1933 la Compañía puso al frente de sus centros a seglares, padres de familia o antiguos alumnos, personas amigas que jurídicamente aparecían al frente de las nuevas Sociedades culturales-docentes. Los profesores marianistas figuraban como profesores contratados a sueldo en una situación de semiclandestinidad de la vida religiosa en la que cada religioso recibió de la Administración Provincial un número de identificación y los colegios una letra con los que eran citados en la correspondencia marianista. La iniciativa partió de la FAE quien impartió la consigna de que todos los centros dirigidos por religiosos se aprestaran a la resistencia pasiva y tomaran posiciones para disputar el campo al enemigo palmo a palmo. Ningún colegio ni escuela debía cerrarse por propia iniciativa de sus directores; nadie había de abandonar los edificios más que obligados por la fuerza.

El Provincial dictó algunas medidas de prudencia, para que los religiosos no fuesen reconocidos como tales; para ello les recomendó que vistiesen totalmente de paisano y que viviesen fuera del colegio, en pensiones y pisos particulares; se procedió a cambiar de ciudad a los religiosos, siendo trasladados a lugares donde fuesen menos conocidos, por lo que en aquel verano hubo un notable trasiego de personal. A los religiosos se les pidió que continuasen su vida normal de trabajo y estudio y que reforzasen la oración y la penitencia para mantener un fuerte espíritu de fe interior que

31

Carta de Murguía al General del 8, VI, 1933 (APM: 101.213); la respuesta de la Admón. Gral., que se estudió en la reunión de directores llevaba fecha del día 12, VI (APM: 101.236) y la respuesta definitiva fue del 30, VI, (APM: 101.241); Murguía a D. Miguel García, 24, IX, 33 (APM: 101.245); durante el mes de agosto -del 2 al 12- tuvo lugar el $18^{\circ}$ Capítulo General de la Compañía al que asistieron P. Gregorio Mtz. de Murguía, P. Domingo Lázaro, P. Salvador López de Luzuriaga y D. Antonio Martínez, allí se concretó con la Administración General la decisión de pedir el estatuto legal de las casas propiedad de la Compañía en las calles Castelló (colegio El Pilar) y Velázquez 21 (sede de la Admón. Provincial) de Madrid, el noviciado de Elorrio, postulantado de Escoriaza, escolasticado de Segovia, casas residenciales en Vitoria y San Sebastián; mientras que los colegios serían transformados en sociedades anónimas. 
contrarrestase la secularización externa de las nuevas condiciones de vida. En estas condiciones, la transformación legal de las obras fue como sigue:

\section{COLEGIO NUESTRA SEÑORA DEL PILAR DE MADRID}

La expulsión de España de los Jesuitas y la aprobación de la Ley de Confesiones ( 2 de junio de 1933) hizo temer a los marianistas españoles la pérdida de las obras escolares de su propiedad. Ya antes del debate en las Cortes de la temida Ley, los Marianistas habían pensado la forma de hacer el traspaso legal de la propiedad de sus colegios. En Madrid fue creada en febrero de 1932 la Sociedad Anónima Cultura y Educación (CESA). A esta sociedad fue entregada la propiedad legal del colegio de El Pilar y bajo esta nueva titularidad las clases se reemprendieron en octubre de 1933.

En efecto, sobre este emblemático colegio de los Marianistas españoles se tomaron las mayores precauciones debido al serio peligro de incautación que se cernía sobre el codiciado edificio. Hay que tener en cuenta que todavía no se habían acabado de pagar las hipotecas que pesaban sobre él para devolver a los marianistas norteamericanos el préstamo dado para la compra del edificio en 1921. Pero en la situación presente, agravada por la subida del dólar, la amortización de la deuda del Colegio del Pilar a las dos Provincias marianistas norteamericanas era un pozo negro que ahogaba la economía de los religiosos españoles. En aquel momento el pasivo de la Provincia de España se eleva a 2.225.625 pesetas, de las que 318.000 se debían a la Universidad marianista de Dayton y 125.000 a la Provincia de San Luis. Además, sobre el edificio el Pilar gravaban diversas hipotecas para avalar las compras de otros colegios marianistas en Ciudad Real y Valencia y las obras del colegio nuevo de Tetuán. Se entiende que la pérdida del Pilar suponía la ruina de la Compañía en España, de ahí todas las posibilidades barajadas para salvar el colegio de un posible embargo estatal.

Para disuadir al Estado de su incautación se decidió destapar todas las deudas e hipotecas que amenazaban la propiedad del edificio y los señores de la CESA propusieron un embargo judicial fundándose en la deuda contraída con los marianistas americanos. Presentada toda la documentación pertinente, el juzgado aceptó la demanda de embargo estableciendo una Administración judicial, al frente de cuya gestión se puso don Aquiles Ullrich Taft, amigo de los marianistas. Al mismo tiempo, se intenta involucrar al Gobierno de los Estados Unidos con una carta del 10 de noviembre de 1932 dirigida al Embajador, señor Laughlin, informándole del asunto, a la vez que por mediación del Inspector general marianista, don Miguel Schleich (de nacionalidad norteamericana) se traban contactos con la institución católica norteamericana National Catholic Welfare Conference para que a través de su director W. F. Montavon se interesase en Washington al Secretario de Estado, si bien fue con el Vicesecretario señor don W. R. Castle con quien trataron y quien manifestó estar "al corriente de la situación de las escuelas y colegios de religiosos en España". Castle aseguró "que él inclinaría al Embajador a proteger nuestros intereses y ver que los $48.000 \$$ fuesen pagados a una entidad americana, caso de que el Gobierno Español confiscase el Colegio". Además, se concertó una cita de don Miguel Schleich con el embajador Laughlin en Madrid ${ }^{32}$

A partir de entonces se procedió por vía judicial. La Universidad de Dayton y la Provincia marianista de Cincinnati, a través de su procurador don Aquiles Ullrich, promovieron autos ejecutivos contra la Provincia de España, ante el Secretario del Juzgado de instrucción $\mathrm{n}^{\mathrm{o}}$ Tres, sobre el pago de un préstamo de 563.960 Pts, intereses y costos. Nuevamente en el mismo Juzgado, el 1 de diciembre de

\footnotetext{
${ }^{32}$ Carta de la National Catholic Welfare Conference del 11, XI, 1932 a D. Miguel Schleich, en APM: caja El Pilar.
}

Hispania Sacra, LXIV, Extra I, enero-junio 2012, 149-177, e-ISSN: 1988-4265 doi:10.3989/hs.2012.028 
1932 el procurador don Julián Zapata y Díaz, en nombre de la Universidad de Dayton, demanda a la Provincia de España para el completo pago de la deuda. El 3 de diciembre los alguaciles y el Secretario se personan en el Colegio del Pilar, y reclaman el pago de la deuda. Lógicamente, el padre Domingo Lázaro, Administrador provincial, declara no tener fondos en metálico para pagar e inmediatamente se embarga el Colegio, con sentencia del 10 de diciembre por parte del Juez. El Colegio quedó bajo un procurador judicial, en la persona de don Aquiles Ullrich.

Pero se desea llegar a una solución definitiva y segura, pues había peligro de que el Gobierno no respetase esta situación jurídica tenida por ficticia ya que los acreedores -las dos Provincias marianistas norteamericanas- y los deudores -la Provincia de España- poseen comunidad de intereses. La solución para salvar el Colegio consistió en traspasar su propiedad a la Sociedad Anónima Cultura y Educación. En el curso 1933-1934, la dirección del Colegio pasó a manos del seglar don Mario González Pons y se escogen a varios titulados seglares para que se hagan cargo de las clases.

El curso comenzó el 2 de octubre sin Misa del Espíritu Santo para no atraer la atención. Doce profesores diplomados seglares, doce diplomados marianistas, más otros doce religiosos sin diplomar formaban el claustro. Como Director nominal figuraba el seglar señor González Pons y subdirectores eran el veterano marianista don Pedro Ruíz de Azúa y don Carlos Eraña. Doce marianistas duermen en las habitaciones de la comunidad dentro del colegio y los doce restantes en cuatro pisos distribuidos por la ciudad.

\section{COLEGIO SAN FELIPE NERI DE CÁDIZ}

En Cádiz, algunos padres de familia habían creado en 1902 la sociedad por acciones "La Escolar, S.A.", que compró el colegio al obispado y se lo alquiló a los Marianistas. Aunque la Compañía de María poseía la mayor parte de las acciones, la propiedad legal pertenecía a La Escolar. En carta del 16 de junio de 1933 el provincial Martínez de Murguía se dirigía a la Junta de accionistas para presentar la renuncia de la Compañía a la dirección y explotación del colegio; y por otra del día 20, dirigida a los gerentes, comunicaba que por la Ley de Confesiones y Congregaciones Religiosas la Compañía de María se vía en la necesidad de rescindir el contrato de alquiler y las mutuas relaciones. A continuación, la Junta General extraordinaria de accionistas y los gerentes, reunidos el 16 de julio de 1933, acordaron rescindir el contrato y La Escolar S.A. tomó en su propiedad la explotación del negocio, en el que la Provincia Marianista de España participaba con 354 acciones sobre un total de 660. El padre Gregorio Martínez de Murguía, ante notario, hizo entrega a los gerentes don Benigno Estévez Martínez, don Adolfo Núñez Palomino y don José Antonio Pérez y Díez-Velasco del material del colegio San Felipe Neri.

33 Carta-informe en AGMAR: 0137.2.41; por el acierto de la operación, D. Aquiles Ullrich fue hecho afiliado de la Compañía de María por petición del P. Gordejuela al P. Jung, carta del 25, XI, 1934 (APM: 103.010), es fotocopia de AGMAR; la correspondencia del provincial español, Gordejuela con el Superior general y demás miembros de la Administración general durante la República, en AGMAR: 077.1.1-292, en orden cronológico.

${ }^{34}$ Gordejuela, Anales, 12 septiembre 1934, 49 y 53 (APM); Martínez, A. 1949. Un alma de educador: 233-234 Burgos;. González Blasco, P. e Isasa, J. 2007: 74-75.

35 Carta de Murguía del 20, VI, 1933, en APM: La Escolar, Correspondencia y Circulares (Sin catalogar). 
Al Colegio se le dota de un carácter civil, cuya titularidad jurídica recae en don Adolfo Núñez Palomino. Será director nominal del Colegio de 1933 al 1936. Al curso siguiente, la dirección regresa a manos del marianista don José Maeztu. Durante la dirección seglar, los gerentes de La Escolar gestionaron ante el señor Obispo la cesión del Oratorio de San Felipe Neri para capilla colegial. Petición que les fue concedida por decreto de la Mitra del 1 de noviembre de 1933.

\section{COLEGIO SAN JUAN BAUTISTA DE JEREZ}

El Colegio de Jerez era propiedad de la Fundación Juan Sánchez, cuyo Patronato había pasado a manos de los Marianistas en 1898. A tenor de la ley de Congregaciones se intentaron dos soluciones. La primera, consistió en que la Administración Provincial ofreciera el Patronato de la Fundación Juan Sánchez a doña Juanita González del Villar, hija de don Juan Bautista González del Villar, uno de los últimos Patronos antes de que el Patronato pasara a los Marianistas; pero esta señora lo rechazó. Entonces, con fecha del 23 de junio de 1933 se pensó en traspasar el Patronato a la Asociación de Antiguos Alumnos, la cual formaría una sociedad anónima. Dicho proyecto dio la pista para la solución final: se resolvió constituir una sociedad anónima industrial mediante escritura pública. La sociedad así constituida se hacía propietaria del colegio, rescindía su relación con la Compañía de María y celebraba contratos particulares con cada uno de los religiosos secularizados y viviendo fuera del edificio escolar. La sociedad anónima titulada "Compañía Jerezana de Cultura S.A." se constituyó el 12 de agosto de 1933 y formaron parte de ella, don José María Aranda y del Río, don Bartolomé Domínguez Romero, don Luis Isasi González, don Salvador Díez y Gutiérrez, don Luis Díez Hidalgo, don Manuel Benítez Lagos y don Alejandro Gordon de la Serna.

Una vez constituida la Sociedad Jerezana de Cultura, se procedió al contrato de arrendamiento. En Jerez, a 19 de septiembre de 1933, ante el notario don Manuel García Atance comparecían el padre Gregorio Martínez de Murguía, como Provincial, el padre Salvador López de Luzuriaga, como Director, y los señores miembros de la Sociedad Jerezana de Cultura, el Presidente, don Salvador Díez Gutiérrez, el Secretario, don Alejandro Gordon de la Serna, y el Tesorero, don Luis Díez Hidalgo, todos antiguos alumnos. La Compañía de María expone que no pudiendo ejercer la enseñanza en la Fundación por prohibición legal, y para que la Fundación continúe con su finalidad traspasa el arriendo del edificio fundacional a la "Sociedad Jerezana de Cultura, S. A." ${ }^{37}$

\section{COLEGIO SANTA MARÍA, VITORIA}

La solución arbitrada para el Colegio Santa María de Vitoria fue crear el 26 de agosto de 1933 una Mutua constituida por antiguos alumnos, padres de familia, reconocida por la Dirección General de

${ }^{36}$ La iglesia de San Felipe Neri estaba declarada Monumento Nacional, pero se hallaba en un triste estado de conservación; La Escolar hubo de restaurarla por cuenta propia, prestando sus servicios al colegio en el curso 1934; cfr. Gordejuela a Jung, 7, X, 1934 (APM: 103.007); Anónimo. 1946. Cincuenta Años de Labor Marianista en España (1895-1945): 53 Madrid; López, Á. 1993. "Cien años de Historia”, en Aranda, C (dir.), Marianistas. Cien años en Cádiz: 77-81 Madrid: ed. SM; González, J. 1983. El colegio de San Felipe Neri: 8081 Cádiz: Publicaciones de la Caja de Ahorros de Cádiz.

${ }^{37}$ Proyecto de creación de una sociedad anónima del 23 de junio de 1933 en AGMAR: 0133.3.56; cfr. Farrás, A. y Barrena, J. 1989, Marianistas en Jerez (1888/1988): 150-152 Madrid: ed. SM; contrato de arrendamiento a la "Sociedad Jerezana de Cultura, S. A.", n 780, en AGMAR: 0133.3.57. 
Seguridad. El 29 de septiembre se firmó la escritura de cesión de derecho de uso del edificio del colegio y de sus bienes muebles a la "Asociación Mutua Minerva", por parte del padre Florentino Fernández Santamaría, Director del colegio. La Minerva estaba representada en calidad de Vicepresidente por don Guillermo Montoya, gran amigo de los Marianistas. A cambio, la Minerva contrató por separado a cada profesor marianista. La primera Junta estaba formada por el Presidente, don Marcelino Oreja, diputado tradicionalista a Cortes; don Guillermo Montoya, Vicepresidente; don Vidal Sanz Ugarte, Secretario; don Benito de la Brena, Tesorero; y don José Lejarreta, don José María Elizagárate y don Pedro Rodríguez, Vocales.

El curso 1933-1934 comenzó con buen pie: el colegio contaba con 429 alumnos, el mismo número que el curso anterior; de Director oficial figuraba don José Lejarreta, si bien la dirección práctica recaía sobre el recién enviado padre Francisco Armentia, no conocido en la ciudad, para sustituir en la dirección al padre Florentino. La comunidad fue renovada con quince religiosos nuevos. Los marianistas deben vivir fuera del colegio, vestir con ropa de color y dejarse barba. Síntoma de la conflictividad y de la inseguridad a consecuencia del triunfo electoral de las derechas, es asesinado don Marcelino Oreja Elósegui, el 5 de octubre de 1934. Entonces el nuevo presidente de la Mutua ha de ser don José Lejarreta, pasando el padre Armentia a ocupar la dirección oficial del centro.

\section{COLEGIO CATÓLICO SANTA MARÍA, SAN SEBASTIÁN}

Respecto al Colegio Católico Santa María de San Sebastián la fuerza económica de la ciudad permitió constituir la sociedad anónima "Asociación Guipuzcoana de Enseñanza S.A.", A.G.E.S.A, con fecha del 5 de agosto de 1933, ante el notario señor don Luis Barrueta y con capital fundacional de 100.000 pesetas. Presidente de la misma fue don Julián Lojendio (abogado), antiguo alumno; Vicepresidente primero, don Juan Zaragüeta (sacerdote); Vicepresidente segundo, don José de Egaña (comerciante); Secretario don Antonio Tamés (comerciante) y los Vocales los señores don Eugenio Rezola (Ingeniero), don Gregorio González de Suso (abogado), don Miguel Urreta (ingeniero), don José María Lizasoain y don Pedro Arsuaga (propietario); Administrador, don Juan Bautista Coutret (marianista); y figuraba en la dirección del colegio don Carlos Santamaría. Constituida la Asociación, en acta del 16 de agosto de 1933 concede poderes al segundo Vicepresidente, don José de Egaña y Minondo, para que formalice ante notario la escritura de arrendamiento del Colegio. AGESA recibía el traspaso gratuito del Colegio sin renta ninguna; a cambio se comprometía a conservar el edificio. A continuación, contrataba por separado e individualmente a cada uno de los profesores religiosos que se les mandó. De director figuró el antiguo alumno Carlos Santamaría y el antiguo director marianista, don Luis Heintz, era el jefe de estudios. Mientras que el superior canónico de los religiosos fue el padre Gregorio Martínez de Murguía, recién terminado su cargo de Provincial.

\section{LAS ARENAS (GUECHO-BILBAO)}

38 APZ: BM. Vitoria. Escritos 1890-1947, Créditos, Poderes; la Mutua de padres de familia fue una fórmula tomada de los Salesianos en una entrevista con el Inspector General de esta Congregación, cfr. Martínez de Murguía al Superior General, 18, IV, 1933 (APM: 101.228).

39 F

Fue aprobada por el Ministerio de Justicia, Dirección Gral. de Registros Notariales, letra A. Núm. 388, expedido en Madrid el 15 de julio de 1933. Documentación de la Constitución de Sociedad "Asociación Guipuzcoana de Enseñanza S A", nº 837. AGESA, en APZ: BM. San Sebastián. Colegio Católico Santa María. Documentos 1889 ... 1972; Ríos, F. y Gastaminza, F. 1987, 100 años de presencia marianista en San Sebastián. 1887-1987: 129-130 Madrid: imprenta SM. 
El Colegio Nuestra Señora del Pilar, en el barrio residencial de Las Arenas (Guecho), era un reducido establecimiento escolar creado por la Compañía de María en 1928 para los hijos de las familias acomodadas residentes en esta zona del ensanche de Bilbao. Para este colegio, ahora ubicado en Gobelas, la solución pasó por constituir una sociedad anónima denominada "S. A. de Enseñanza y Educación, Colegio del Pilar". Al frente de la Junta se puso a don Antonio Menchaca, don Gabriel María Ibarra, don Juan Prado y don Venancio Echeverría. Una vez cedido el uso de la propiedad, la sociedad anónima procedió a nombrar director a don Gregorio Ortuondo, licenciado en Letras, bajo cuya dirección "se seguirán aplicando los mismos métodos pedagógicos que acreditaron mientras lo regentaron los Hermanos Marianistas". Los religiosos, buscaron alojamiento fuera del local escolar y contratados como profesores, continuaron desempeñando su labor.

Pero esta solución no trajo buenos resultado académicos. La nueva dirección seglar no fue capaz de mantener la misma disciplina que los religiosos y éstos no supieron organizar el trabajo en dependencia de los titulados seglares al frente de la obra; bajó la disciplina y aumentó el número de suspensos en los exámenes finales. Comenzó a descender el número de alumnos y el colegio vivió una existencia amenazada (una de las causas eran los altos precios de las matrículas). Los mismos socios retiraron a sus hijos del centro y la Sociedad perdió vigor; el Colegio no se abrió después de la guerra. ${ }^{4}$

\section{COLEGIO NUESTRA SEÑORA DEL PRADO (CIUDAD REAL)}

Las medidas secularizadoras se extremaron en Ciudad Real donde la conflictividad obrera había sido particularmente alta en el campo. Allí se podía salvar únicamente el Colegio Nuestra Señora del Prado (propiedad de la Compañía de María), porque el Instituto Popular de la Concepción (que era un Patronato de la Diócesis confiado en 1916 a los Marianistas) "no tenía asidero ni teníamos bienes comprometidos" en él. Entonces se decidió traspasar la propiedad del colegio a una sociedad anónima bajo la titularidad y dirección técnica de don César Díez Hurtado, licenciado en Ciencias Físicas y Químicas, que era padre de familia del colegio y católico señalado. La dirección oficial recayó el licenciado en Historia don Francisco Cervera, empleado en el catastro y dedicado a la enseñanza. Se estableció un contrato privado con la Compañía de María para que el colegio volviera a la propiedad de los Marianistas cuando cesase la situación actual. El superior de la comunidad, don Lino Esquibel, fue nombrado subdirector. Pero no hubo buen entendimiento entre ambos directores, obligando a los superiores a cambiarlo por don Rafael Rodrigo.

En Ciudad Real se cambió completamente a los religiosos y llegaron los nuevos profesores secularizados en sus apariencias externas y viviendo todos en pensiones. Extremando las medidas de seguridad, la comunidad decidió cerrar la capilla con candado, quitar los crucifijos de las clases, suprimir el capellán y las actividades religiosas y el director seglar adornó las paredes de su despacho con fotos de actrices y toreros. "Llevamos pues la secularización hasta el último extremo", hasta causar el desconcierto de las familias que llegaron a dudar del carácter confesional del centro y comenzaron a retirar a sus hijos. El padre Martínez de Murguía hubo de intervenir para recomendar sensatez y no extremar las medidas preventivas de secularización fingida; con esta intención, en diciembre de 1933

${ }^{40}$ APZ: BM. Vergara-Yurre-Las Arenas..., carpeta: Las Arenas; AGMAR: 0152.10.105.

${ }^{41}$ La situación la expone el P. Martínez de Murguía al Superior General, 16, VI, 1934 (APM: 101.293) y Gordejuela a D. Miguel García, 27, XI, 1935 (APM: 103.041).

${ }^{42}$ Quelques impresions des communautés d'Espagne (APM: 101.266); ver la situación de Ciudad Real en Congregatio de Causis Sanctorum (Torres, E.) 1990: 21 Roma; D. Lino Esquibel a la A.G., X, 1933 (APM: 101.251); AGMAR: 0119.14.37 y 38 . 
fue enviado de capellán el padre Florentino Fernández. Mientras que en todas las obras, el alumnado había crecido de número a pesar de las medidas secularizadoras, en Ciudad Real se perdió alumnado.

"No hay en nuestras obras más que una excepción: el Colegio Nra. Sra. del Prado de Ciudad Real, que de 300 y pico alumnos que llegó a contar hace dos años (1932-1933), no llegaba a 140 al empezar el presente curso (1935-1936). ¿A qué atribuir esta anomalía (...)? Hay una razón general que contribuyó en gran medida a esa disminución: hubo religiosos que querían aparecer no sólo seglares sino hasta indiferentes y despreocupados desde el punto de vista religioso, que a todo trance querían ocultar su carácter. (Algunas familias habían comunicado directamente al Provincial) 'Ya que no son ustedes religiosos me es más cómodo y ventajoso llevar a mi hijo a un Colegio más cercano'. Si decimos que las familias nos buscan como educadores de sus hijos, más que nuestras condiciones de profesores buscan nuestro carácter de religiosos educadores."

\section{ESCUELAS EN RÉGIMEN DE PATRONATO}

La Compañía no tomó directamente medidas legales con las escuelas gratuitas y de patronatos, cuya titularidad e inmuebles no eran de su propiedad; sino que las tomaron sus titulares para asegurar la permanencia de los maestros marianistas.

El Colegio del Santo Cristo, en Villarrín de Campos (Zamora), por Decreto del Secretario del Obispado de Astorga, con fecha del 5 de septiembre de 1933, transformó la Fundación en escuela parroquial bajo la autoridad directa del señor Obispo. Entonces, por medidas de prudencia, al comenzar el curso 1933-1934, se dejó la dirección y don Antonio Segura -que era muy conocido en el pueblofue sustituido por don Lucio de Miguel; pero ya no como director sino a título de maestro particular contratado.

Un caso especial de decaimiento durante estos años republicanos fue el Colegio San José de Suances (Santander). Asistimos a un síntoma característico de los colegios creados por una Fundación, que ante la crisis económica de 1929 vieron cómo sus capitales fundacionales se quedaron menguados para asegurar la supervivencia económica

de los religiosos al frente de la obra. Para asegurar la permanencia de los Marianistas, el 17 de agosto de 1932 se tuvo una reunión de la Junta del Patronato con el Provincial padre Martínez de Murguía, el Inspector don Alonso Thibinger y don Ciriaco Calzada, Director del Colegio. La Compañía de María pedía establecer en el colegio el Bachillerato de pago para mejorar la situación económica y asegurar la permanencia los Marianistas. El Patronato aprobó la petición de los religiosos, pero algunas familias de la villa denunciaron el cobro de matrícula de la Segunda Enseñanza, por ser práctica contraria al

${ }^{43}$ Informe del provincial Gordejuela, al Capítulo Provincial (4, III, 1935) p. 6-7 (APM: $33^{\circ}$ Capítulo Provincial, Marianistas-Provincia España); carta de Gordejuela a Jung, 19, XI, 1934 (APM: 103.009).

${ }^{44}$ Obispado de Astorga. Secretario. Decreto del 5, IX, 1933, dado por el Arcipreste Secretario Licd ${ }^{\circ}$ José Huertas, el 26, IX, 1933 y Junta Provincial de Beneficencia de Zamora $N^{\circ}$ 195, al Alcalde de Villarrín, 23, X, 1933: relación de propiedad del Colegio Stmo. Cristo de Villarín, en Requerimientos mediante Oficios de la Inspección de Primera Enseñanza (1922-1936), en APM: caja Villarrín. 
carácter gratuito y benéfico de la Fundación. El asunto pasó por varias instancias docentes, hasta que el Ministerio de Instrucción Pública instruyó un expediente de cese en las funciones del Patronato.

En estas circunstancias se hacía muy difícil la permanencia de la comunidad marianista y como la Ley de Confesiones venía a complicar las cosas, el padre Martínez de Murguía comunicó en carta del 20 de agosto de 1933 al Presidente del Patronato: "En cumplimiento de la Ley de Confesiones y Congregaciones Religiosas (...) nos vemos en la necesidad de rescindir el contrato que teníamos firmado con ustedes. (...) Al cesar, muy a pesar nuestro, y sólo por imperativo categórico de esa Ley". 46 Sin embargo, los Patronos se aferraron a la Compañía de María para impedir su retirada del colegio y el 27 de septiembre de 1933 los Albaceas Patronos acordaron redactar un nuevo contrato que se firmó por un año. ${ }^{47}$ El nuevo contrato resultaba muy ventajoso para la Compañía, que conservaba plena libertad pedagógica y veía incrementados los sueldos de sus profesores. Gracias a esta reforma de la Fundación se pudo continuar en la villa de Suances. Pero por la descapitalización de la Fundación, los Marianistas no volvieron después de la guerra.

Dada la situación legal en que la Ley de Confesiones había dejado a los colegios, la Administración Provincial no pudo ejercer su gobierno sobre los establecimientos escolares; y en el Capítulo Provincial de enero de 1934 no se pudo legislar nada sobre las obras. De ahí que el Provincial reconoció que "más que Capítulo propiamente dicho, ha sido una reunión de familia para cambiar impresiones sobre el estado de la Provincia."

\section{NUEVAS FUNDACIONES EN VALENCIA, ELORRIO, SAN SEBASTIÁN Y SEGOVIA}

Otras de las medidas para sortear la prohibición legal a ejercer la docencia fue abrir colegios con aspecto seglar; donde los religiosos podían pasar desapercibidos. Se piensa en las ciudades de Valencia y Sevilla. A este fin, el nuevo Inspector don Antonio Martínez viajó a Valencia a reconocer un colegio completo de Primera y Segunda Enseñanza, con internado, pero con peligro de desaparición por falta de dirección técnica de sus propietarios y fundadores, los sacerdotes diocesanos don Joaquín y don Miguel Bataller y de su hermana doña Asunción. El colegio, llamado "Internado de Malvarrosa", estaba ubicado en medio de una gran finca en el barrio del Cabañal y había sido creado para recoger a los alumnos del Colegio de San José que los padres Jesuitas habían dejado con motivo de su expulsión de España. Después de la entrevista, en septiembre de 1933 se llegó al acuerdo de encargar a los Marianistas la dirección que funcionaba sin espíritu pedagógico ni educativo, por falta de experiencia y de personal adecuado.

45 Documentos: "Complemento de las BASES del año 1928", "Junta Provincial de Beneficencia. Santander. $n^{\circ}$ 596. 2 mayo 1933 el Gobernador-Presidente al Presidente del Patronato" y "Respuesta de la Junta al Gobernador Civil y Presidente de la Junta Provincial de Beneficencia", en APM: Colegios. Suances.

46 Carta del Provincial y expediente del Ministerio de Instrucción Pública-Fundaciones benéficas (846) del 2, VIII, 1933-Madrid, en APM: Colegios. Suances: carpeta Bases para implantar en el Colegio la Segunda Enseñanza.

47 "Bases por las que debe regirse el Colegio de San José. Fundación Gómez Quintana. Villa de Suances", en APM: Colegios. Suances. Carpeta Bases para implantar en el Colegio la Segunda Enseñanza.

${ }^{48}$ Murguía al P. Sorret, 8, VI, 1933 (APM: 101.231); cartas de Gordejuela a D. Miguel García del 7, VIII, 1935 (APM: 103.031), y del 28, X, 1935 (APM: 103.035), de D. Miguel a D. Miguel Schleich, 12, IX, 1935 (APM: 103.032) y en Gordejuela, Anales, 55, 81, 83, 85 y 87 (APM); Julián Díaz de Guereñu, Fundación 
En octubre de 1933 comenzaron las clases de este centro, inicio de la presencia marianista en Valencia. Fue un comienzo duro para alcanzar la disciplina en los alumnos. El curso 1934-1935 se inauguró con nuevo director en la persona del religioso don Juan José Aranzábal y de capellán Cayo Fernández de Gamboa. Ambos hombres enérgicos y de gobierno que mejoraron las instalaciones, el orden y la disciplina. Así, creció el prestigio del centro y aumentó el alumnado.

Los hermanos Bataller ofrecieron la venta del colegio a los Marianistas. Pero no se llegó a un acuerdo económico y los religiosos se retiraron al terminar las clases en julio de 1935. El señor Arzobispo, don Prudencio Melo y Alcalde, que conocía a los Marianistas por haber sido obispo de Vitoria y de Madrid, les retuvo en Valencia y les ayudó a buscar un local. El prelado tenía sus buenas razones, pues con la República, en la provincia de Valencia se dio el caso de llegar a perderse edificios escolares estatales.

Los religiosos encontraron un local modesto capaz de tres clases de primera enseñanza, en la zona del ensanche, calle Conde de Altea, 41. Por figurar como escuela de primera enseñanza, toda la documentación y la dirección oficial se pusieron a nombre de don Julián Díaz de Guereñu, que era titulado de Magisterio; si bien, el director efectivo era don Juan José Aranzábal, Licenciado en Letras. El 15 de septiembre de 1935 comenzaron las clases del Colegio Nuestra Señor del Pilar, con 16 alumnos y tres profesores: don Juan José Aranzábal, don Julián Díaz y don Celestino Martínez. El Colegio creció y terminado el curso se pensó en ampliarlo para la segunda enseñanza. Pero ante el mal cariz de la vida política se alquiló un piso cercano para establecer en él un Colegio-Academia de Segunda Enseñanza, bajo una dirección oficial distinta, al frente de la cual se puso al médico y buen amigo don Jerónimo Cabanes. En esta situación se estuvo hasta la irrupción de la Guerra.

Dentro de la misma estrategia se aceptó en la villa de Elorrio (Vizcaya) la escuela del Beato Valentín Berriochoa, a petición del sacerdote don Juan Murua, quien fundara junto con don Fermín Fernández Sáenz, el 15 de septiembre de 1933 unas escuelas católicas. Según las Bases de Creación, don Fermín era el Director, y el centro se componía de cuatro clases de primera enseñanza, con unos cuarenta alumnos cada clase. Don Juan Murua abonaría 3.000 pesetas anuales a cada profesor y también correría con el mantenimiento del inmueble y del alojamiento de los maestros. La enseñanza había de ser católica; sin color político y "se cultivará el vascuence por ser lengua del país". El local fue donado por las señoras de Vidásolo, en la planta baja de su propia mansión. Después de buscar a maestros entre los Escolapios y Maristas, don Juan Murua se dirigió al Padre Maestro, Abdón Pereda, para interesar a los Marianistas. El padre Abdón lo refirió al Provincial y la escuela fue aceptada, con don Fermín Fernández en la dirección y el joven marianista don Venancio Arbulo.

Doña Encarnación Murua, hermana de don Juan, había fundado en 1931 con la Condesa viuda de Láriz la escuela "San Ignacio" en Villa Ulía, San Sebastián, unida a la Acción Católica. Situada en

de Malvarrosa y sedes diferentes del Colerio Ntra. Sra. del Pilar en la ciudad de Valencia, cuaderno promanuscripto (APM); Aranzábal, J. J. 1985. "Marianistas en Valencia", en Otaño, J. L. Marianistas en...: 60-72 Madrid: Fundación Santa María; las cartas del P. José Asenjo del 21, XI, 1933 y del 4, II, 1934 a D. Miguel García, en AGMAR: 0157.4/8 y 18; Luis María Lizarraga, Historia del Colegio Ntra. Sra. del Pilar. Valencia, en APZ: BM. Valencia; Salaverri, J. M. 2007, 75 años de presencia marianista en Valencia (1933-2008): 11-21 Madrid: SPM ed. S. M.

${ }^{49}$ Fernández Soria, J. M. 1994. "La educación en Valencia durante la República y la Guerra Civil" en Buenaventura Delgado (coord.), Historia de la Educación en España y América, III: 830-836 Madrid.

Documentación en APZ: BM. Elorrio: Escuela V. Berriochoa: hay Bases de la Creación y Anales.

Hispania Sacra, LXIV, Extra I, enero-junio 2012, 149-177, e-ISSN: 1988-4265, doi: 10.3989/hs.2012.028 
el barrio de Gros, la frecuentaban niños pobres de clase obrera afiliada a partidos de izquierda y de ambientes descristianizados, aunque la mayoría de los alumnos provenían de familias cristianas. La escuela era semigratuita, estaba emplazada en la parroquia de San Ignacio y había sido confiada a unos maestros seglares. Pero la fundadora no estaba satisfecha del modo en que éstos la regentaban por lo que recurrió a los Marianistas.

Se llegó a un acuerdo con la Compañía, pero sin firmar contrato. El curso comenzó en octubre de 1933 bajo la dirección de don Antonio Segura Jáuregui, asistido por don Isidro Echevarría, en un local de la calle Zabaleta. Tuvieron gran éxito de asistencia y al terminar el año contaba con 120 alumnos repartidos en tres clases. En 1934 se añadió un tercer religioso y nuevo director en don Victoriano Martínez. Pero la presencia marianista contó con una existencia efímera, pues en 1935 los maestros marianistas abandonaron la escuela, falta de recursos económicos, y fueron reemplazados por los Maestros Manjonianos de las Escuelas del Ave María.

En Segovia se adquirió, a petición del señor Obispo, Luciano Pérez Platero, la "Escuela del Santísimo Cristo del Mercado" que abrió sus aulas el 1 de octubre de 1934, situada a trescientos metros del Escolasticado marianista. La escuela era gratuita y patrocinada por la Asociación Católica de Padres de Familia "para contrarrestar la perniciosa influencia de las escuelas laicas del Gobierno". Estaba situada en un barrio de la estación de ferrocarril, en el que abundaban los obreros de filiación socialista, que se encontraban religiosamente muy abandonados. La obra se aceptó con la finalidad de tener una escuela al lado del Escolasticado para las prácticas pedagógicas de los escolásticos.

Su director fue don Ildefonso Salazar ayudado por los escolásticos, que trabajaban sin salario, pero don Ildefonso recibía 2.000 pesetas anuales pagadas por los Padres de Familia, según el contrato. De esta manera se empezó con dos clases de 40 niños cada una. La escuela se hizo famosa en Segovia por su orden y resultados académicos, y por la participación del coro de niños en la misa de la parroquia vecina.

\section{BALANCE POSITIVO DE LA SECULARIZACIÓN DE LAS OBRAS}

Las elecciones del 19 de noviembre de 1933 dieron el triunfo aplastante al bloque de derechas. Entre los objetivos de su programa electoral estaba la revisión de lo que llaman "legislación laica y socializante" y piensan que es posible dar continuidad a una República corregida de los excesos radicales; para ello estimaban que la Constitución era reformable. El bienio reformista había terminado.

El padre Lázaro comentó en la revista Atenas de noviembre de 1933 los resultados de las elecciones para advertir a los religiosos y religiosas en la enseñanza que no se duerman en quiméricas ilusiones y les pone en guardia para que no caigan en una desmedida euforia: "¡Señores: y ahora, a empezar!" Considera que en las urnas han salido vencedores "los españoles que piensan y sienten en español", la España que tiene el "pulso fuerte". La otra parte, la vencida, es considerada -con un sentido rupturista de la totalidad española- como la no-España: sus rivales habían puesto todo su empeño en matar a España "por brutales empellones del sectarismo social y antirreligioso"; son "los

${ }_{52}^{51}$ Sobre Villa Ulía, cfr. AGMAR: 0152.2.1 y 2.

52 Carta a D. Miguel García, 28, X, 1935 (APM, 103.035); recuerdos de D. Ildefonso Salazar y de D. Pedro Legorburu en APM: archivador 220, carpeta 4; Salazar, I. 1985. "Marianistas en Segovia, Carabanchel Alto y Barcelona", en José Luis Otaño, Marianistas en..., 74-79. 
enemigos de España" que "no han muerto ni se dan por vencidos ni cejarán en sus propósitos." Al radicalismo de izquierdas replicaba el radicalismo de la derecha; ambos con su extremismo excluyente apropiándose de la verdadera España para sí y expulsando al que no pensaba de igual manera.

La situación educativa, se estabilizó. No hubo más sobresaltos legales. El éxito de la fórmula de transformación de los colegios en sociedades anónimas, manteniendo la identidad católica de los mismos, la regularidad de los religiosos en su vida comunitaria, rezos, estudios y trabajo permitió volver a la normalidad. El bienio conservador trajo tranquilidad y confianza a los religiosos, que abandonaron su dispersión en fondas y en casas de amigos y familiares y regresaron a vivir en los colegios, retomando la vida regular. Aún dentro de la preocupación, existía otro estado de ánimo más sereno y el nuevo Provincial, Marcos Gordejuela, reconoce ante el Capítulo Provincial de 1934 que "no cabe duda que a pesar de las deficiencias particulares que han podido notarse, producidas en parte, por la desorientación de los primeros días nuestros religiosos, por regla general, siguen con el mismo espíritu religioso que los animaba en años anteriores, y que las medidas secularizadoras han hecho en ellos poca mella, (...). Se puede asegurar que hasta la fecha, la secularización no ha producido defecciones entre nosotros (...). Sin embargo, no parece todavía, haber llegado la hora de volver a la uniformidad religiosa".

\section{CRECIMIENTO ANORMAL DE LAS OBRAS MARIANISTAS}

Se puede decir que la Compañía de María había sabido responder a la legislación docente y anticlerical del bienio reformista, sobre todo, a las medidas secularizadoras de Ley de Confesiones. De hecho, en el Personnel de la Société de Marie. España. Décembre 1933, el número de profesos había ascendido hasta 352 (46 más que en 1931), de los que 43 estudiaban en el Escolasticado y 5 en el Seminario de Friburgo, 299 estaban empleados en las obras de España y 9 en servicios en el extranjero. Los novicios eran 15 y sólo los postulantes habían descendido el bienio reformista, pasando de los 70 de 1931 a los 29 actuales, por el temor de las familias y de los mismos religiosos en tiempos tan agitados. Pero con la confianza que daba la vuelta al poder de las derechas, la vida religiosa marianista volvió a sus cauces habituales y el número de religiosos se estabilizó, en medio de una situación que podemos definir como de desarrollo anormal de las obras de la Provincial. Así, atendiendo al Personal marianista de 1935, la institución contaba con 350 religiosos, de los que 22 estaban empleados en otras Provincias; había 24 sacerdotes, 35 escolásticos en Segovia, 17 novicios y el número de postulantes se había recuperado hasta alcanzar su cifra normal, en 94 muchachos. Cifras que hacían mirar el futuro con esperanza. De hecho, en medio de la agitada vida política de la nación los patronos y directores

53 Tuñón de Lara, M. 1981. "La Segunda República", en Historia de España: IX 172 Barcelona: ed. Labor; Marías, J. 1993-1994. "España ante la historia y ante sí misma (1898-1936)", en Laín. P. La edad de plata de la cultura española (1898-1936), en Jover, J. M. (dir.). Historia de España Menéndez Pidal: XXXIX/1 119124 Madrid: Espasa-Calpe; Martínez, A. 1949: 262-265.

${ }^{54}$ La nueva inscripción de la Compañía de María en el Ministerio de Gracia y Justicia por mandato de la Orden del 4, I, 1935, en cumplimiento del a. 26 de la Ley de Confesiones se hizo con fecha del 9 de julio de 1935, Subsecretaría de Asuntos Religiosos, Sección, 2. Están registradas las comunidades religiosas a título de Marianistas, PP. de la Compañía de María: Madrid ( $n^{\circ} 4080$, legajo 188), Segovia ( $n^{\circ} 4081$, leg $\left.{ }^{\circ} 189\right)$, San Sebastián -Aldapeta- ( $\left.n^{\circ} 4082, \operatorname{leg}^{\circ} 189\right)$, Escoriaza ( $\left.n^{\circ} 4083, \operatorname{leg}^{\circ} 189\right)$, Elorrio $\left(n^{\circ} 4084, \operatorname{leg}^{\circ} 189\right)$ y Vitoria (n 4085, leg 189 ); cfr. Gordejuela a D. Miguel García, 28, X, 1935 (APM: 103.035). 
proceden al arreglo y renovación de instalaciones escolares; a la adquisición de terrenos y propiedades para nuevas obras educativas y casas de formación.

Al final del bienio reformista los colegios marianistas de Primera y Segunda Enseñanza seguían siendo los mismos en las poblaciones de San Sebastián, Vitoria, Madrid, Ciudad Real, Jerez de la Frontera, Cádiz, Tetuán y Las Arenas. También los religiosos se habían mantenido en las escuelas de primera enseñanza del Colegio del Santísimo Cristo en Villarrín de Campos, la Casa de Observación de Vitoria, el Instituto Popular de la Concepción de Ciudad Real, el Colegio San José de Suances, el Colegio Ntra. Sra. del Carmen de El Royo, la escuela municipal de Elgoibar y el colegio de Ntra. Sra. de la Asunción de Yurre. Paradójicamente, en tiempo de restricciones legales a la enseñanza congregacional, habían aumentado el número de establecimientos dirigidos por los Marianistas. La causa se encuentra en que la estrategia de contratar personal seglar en los grandes colegios secularizados arrojó de sus puestos laborales a un grupo de religiosos, para los que hubo que crear o buscar nuevos centros escolares. De aquí que en Personal provincial de diciembre de 1933 aparecen más establecimientos que en el de 1931, al advenimiento de la República. Estos nuevos establecimientos fueron el Colegio Atenas, en la calle Juan de Mena de Madrid, Villa Ulía en San Sebastián, la escuela Cristo del Mercado en Segovia, el colegio Valentín Berriochoa de Elorrio, el Colegio Ntra Sra del Pilar en Valencia y la Escuela Benito Nazar en Buenos Aires. Ante este crecimiento, el padre Martínez de Murguía propuso para Inspector de los establecimientos escolares marianistas al joven y activo director de la segunda enseñanza del colegio de El Pilar de Madrid, don Antonio Martínez. Don Antonio relevó a don Alonso Thibinger en agosto de 1933; era discípulo del padre Domingo Lázaro y durante el franquismo será una notable autoridad en la política docente del país.

A partir del curso 1934-1935 gobierna la Provincia de España una nueva Administración Provincial formada por el Provincial, padre Marcos Gordejuela, y el señor Inspector, don Antonio Martínez. La nueva Administración se encontró con el reto de responder a crecientes demandas de plazas escolares, pues las medidas tomadas por la II República contra la enseñanza de los religiosos habían provocaron un desarrollo anormal de las obras de la Provincia. De hecho, desde 1931 al 1935 se fundaron 7 nuevos colegios: 2 en Buenos Aires, 1 en Valencia, 1 en Juan de Mena (Madrid) y 3 escuelas -San Sebastián, Elorrio y Segovia-. Además aumentó el número de alumnos en los establecimientos marianistas. El crecimiento de alumnos vino exigido por las mismas familias católicas. Los padres secundaron la prohibición de los obispos de matricular a los hijos en escuelas neutras o ateas; al tiempo que sintieron como un ataque a sus creencias las leyes contra la enseñanza de las Congregaciones, aumentando, así, la preocupación por la educación cristiana de sus hijos. Preocupación que "ha sido (la causa), en parte, del aumento de la población escolar de nuestros Colegios -declaraba el provincial Gordejuela ante los capitulares de 1935-. Todos ellos tienen hoy día, más alumnos que hace dos años y algunos, notablemente más."

55 Informes del P. Gordejuela y D. Antonio al Capítulo Provincial, del 4, III, 1935; y el informe económico de D. Lino Esquiquel del Capítulo siguiente (1936) da cuenta de las obras de mejora de Vitoria, con la instalación de la calefacción por 60.000 pts, y acondicionamiento de Escoriaza; también L'Apôtre de Marie 283: 585-588.

${ }^{56}$ Martínez de Murguía a Superior General, 28, VI, 1933 (APM: 101.234); ya el P. Domingo había señalado al joven director de la sección de pequeños del colegio del Pilar, en el "informe" del 14 de junio de 1929, en AGMAR: dossier Mtz. de Murguía. 33; Martínez, J. 1980: 130 Madrid.

${ }^{57}$ Informe del provincial Gordejuela al Capítulo Provincial del 4, III, 1935; El Informe de D. Antonio al Capítulo arroja un volumen de 4.784 alumnos en un total de 22 centros marianistas.

Hispania Sacra, LXIV, Extra I, enero-junio 2012, 149-177, e-ISSN: 1988-4265 doi:10.3989/hs.2012.028 
La situación legal de los colegios marianistas ya no cambió hasta que terminada la guerra civil don Antonio Martínez recuperó la propiedad legal de las obras para la Compañía de María. El único cambio después de la guerra fue el abandono de los establecimientos tenidos en régimen de Fundaciones y Patronatos, debido a la depreciación de la peseta y la descapitalización del país, que empobrecieron dichas Fundaciones. No pudiéndose sostener en estas obras de carácter social, y por lo regular en medios rurales o semiurbanos, los Marianistas se retiraron de ellas, concentrando sus efectivos en los grandes colegios completos de primera y enseñanza ubicados en capitales de provincia, y que eran propiedad de la Compañía. Pero este capítulo ya nos saca fuera de nuestro período de estudio.

Respecto al tiempo restante de vida de la República hasta la catástrofe de la guerra, los religiosos no tuvieron más sobresaltos que los causados por la convulsa vida política nacional: La revolución de octubre de 1934, el triunfo electoral del Frente Popular en febrero de 1936, con el regreso de la angustia causada por la multiplicación de los actos de violencia política y civil y, finalmente, la guerra. El comentario a la revolución de Asturias y a la muerte violenta de los eclesiásticos que hace el padre Lázaro en el número de octubre de la revista Atenas expone el presentimiento de la guerra y de una persecución religiosa: "se olía la barricada" y lo sucedido no es sino un "modesto ensayo de la gran representación que, sin mucho tardar, y si Dios misericordioso y apiadado de España, no lo impide, se dará, para ruina de las causas más sagradas y vergüenza sempiterna de España. Confiemos, sin embargo, en que así no sea. Pero ¡alerta!...". De los religiosos asesinados Lázaro afirma que son "víctimas propiciatorias" de "esos programas" de descristianización, de "odio vesánico o de la irreligión"; y que su tarea docente nacía de los tres grandes principios unitarios y fundamentales de la mentalidad católica durante la Restauración para definir España: "han caído cumpliendo el duro deber que la Familia, la Patria, la Religión, les imponía". A pesar de los desórdenes públicos, las obras marianistas situadas en las regiones afectadas por las huelgas y actos revolucionarios solamente sufrieron la paralización de la actividad escolar durante dos semanas; las Arenas, Escoriaza, Suances, Elorrio y Elgoibar estuvieron incomunicadas durante unos días, sin que hubiera que lamentar ningún percance.

Pero la vida colegial de las obras marianistas continuaba su marcha normal, en medio de aquella tensión política y social. Tres grandes urgencias acuciaban a la Administración Provincial: encontrar una salida al internado de la Malvarrosa en Valencia, construir un nuevo colegio en Tetuán y darle una solución al colegio de San Felipe Neri de Cádiz, cuyo estrecho edificio no podía acoger tanta demanda de alumnado como recibía.

En Cádiz, al final del curso de 1933-1934, los gerentes de La Escolar emprendieron negociaciones para adquirir el campo de deportes popularmente conocido por "Mirandilla", perteneciente a la asociación recreativo-deportiva-cultura "Asociación de Antiguos Alumnos de la Escuela de San Miguel Arcángel. Fundación Moreno Mora", sita en la calle Obispo Félix Soto, antes Mirandilla, de donde le venía su nombre. ${ }^{59}$ Puestos en contacto con el Secretario y Presidente; y en

${ }^{58}$ Sobre la revolución de Asturias, Cárcel, V. 1995. Mártires españoles del siglo XX: 66-71, $247-249$ Madrid: BAC, hace notar que ya hubo una verdadera persecución religiosa antes de la guerra civil.

59 "Certificado de Constitución de la Mirandilla" en APM (documentos sin catalogar); La Mirandilla era una asociación de antiguos alumnos de la mencionada escuela, constituida en 1912 por iniciativa del director de la misma, el Rvdo. Hermano Domingo José, y reconocida legalmente en el Gobierno Civil de la provincia de Cádiz el 30, I, 1924; la sociedad tenía fines recreativos, culturales y benéficos para que los asociados 
Junta extraordinaria el 24 de julio de 1934 acordaron la venta del campo deportivo a La Escolar. Seguidamente, la Junta directiva del Mirandilla dio permiso para proceder a la venta por 125.000 pesetas. De parte de la Compañía de María el visto bueno estaba dado. Con fecha 19 de noviembre de 1934, los Gerentes de La Escolar firmaron el contrato de adquisición del campo de la Mirandilla fuera de Puerta Tierra en la avenida Ana de Viya, para campo de juegos. Los alumnos de San Felipe Neri dispondrían de un campo de deportes pero en los gerentes de La Escolar y en los Marianistas anidaba la intención de levantar un nuevo pabellón escolar donde trasladar el alumnado de San Felipe; empresa que sólo se podrá hacer después de la guerra.

En cuanto al Colegio Nuestra Señora del Pilar, en Tetuán, capital del Protectorado de Marruecos, se vive una situación similar. El colegio reside en una casa de vecinos: los alumnos tienen los recreos en la calle con riesgo de ser atropellados por los automóviles; la comunidad religiosa convive "con las familias en el inmueble con peligro moral para los religiosos", en el criterio del director, don Ángel Chomón. ${ }^{60}$ El local no responde a las necesidades de los 300 alumnos, por cuyo motivo el Consejo Provincial del 2 de enero de 1935 aprobó la construcción de un nuevo Colegio, sobre unos terrenos que habían sido comprados en octubre de 1930, en el Paseo de las Palmeras. El 14 de mayo de 1935, la Administración General dio su autorización para construir el nuevo centro por un importe de 600.000 pts. Las obras dieron comienzo el 20 de agosto de 1935 para terminarlo a fines de octubre de 1936. Lógicamente, la Guerra Civil paralizó los pagos de la deuda hasta $1941{ }^{6}{ }^{6}$

En Argentina los Marianistas había recibido la dirección de la Escuela "General Benito Nazar". Pero las discrepancias pedagógicas con las damas de la Obra de la Conservación de la Fe para dirigir un centro con el talante de la pedagogía marianista aconsejaron a don Pedro Martínez Saralegui a crear una obra propia, sin abandonar la escuela Benito Nazar. Don Pedro adquirió un palacete para fundar un colegio, situado en la calle Rivadavia, 6340-46 en la arteria principal y más larga de la ciudad. Así el Colegio se podría surtir de alumnos de pago. Estima el inicio de la nueva obra para el mes de diciembre de 1934 y pide a Madrid seis religiosos. Se le envían seis maestros que zarparon de Cádiz el 22 de diciembre de 1934 y llegaron a Buenos Aires el 8 de enero.

El Colegio Marianista inició sus clases el 11 de marzo de 1935, modestamente con 10 alumnos de segunda enseñanza y algunas clases de primaria, todos de pago. Don Pedro pasó a ser su primer director y de la Escuela Benito Nazar se hizo cargo don Florencio Fernández en una comunidad formada por ocho religiosos. De esta guisa se tienen en Buenos Aires dos obras colegiales. Buenos Aires era una ciudad en plena expansión; recibía la riqueza de todo el país y a su puerto llegaban barcos de todas partes del mundo; bien podía esperar don Pedro que el Colegio saliese para adelante.

Los últimos meses de estabilidad política republicana, desde el triunfo electoral del Frente Popular en febrero de 1936 hasta la conspiración del general Mola y el alzamiento de los militares, no cambió la situación legal de los colegios marianistas; sí la inseguridad en las vidas de los religiosos.

mantuvieran las prácticas cristianas aprendidas en el colegio y promover la cultura física entre los alumnos actuales.

${ }^{60}$ Cartas de D. Ángel Chomón, director, a D Miguel Schleich del 18, III, 1934 (APM: 101.275) y de Gordejuela a Jung, 17, X, 1934 (APM: 103.007).

${ }^{61}$ Gordejuela, Anales, 77, 81, 83, 85 y 91; Villazán, B. 1988. Marianistas en Marruecos: 42 Madrid: ed. SM; y revista 1940. Colegio Ntra. Sra. del Pilar, Tetuán (Marruecos), Bodas de Plata. Album conmemorativo 1915-1940: 44 Tánger; contrato con la empresa Agromán en APM: caja El Pilar. 
La revolución de octubre había puesto de relieve que no existía un consenso político en torno al régimen republicano. Con la caída de Lerroux, en octubre de 1935, se polarizaron las fuerzas políticas entre la derecha y las izquierdas. Se convocan elecciones y todos los grupos parlamentarios se aprestan a formar los frentes electorales. El 15 de enero de 1936 se realiza el pacto constitutivo del Frente Popular, con el programa de restaurar la legislación del bienio reformador y amnistiar a los revolucionarios de octubre de 1934. Por su parte, la derecha se unió en el Bloque Nacional integrado por CEDA, con acuerdos parciales con monárquicos, tradicionalistas y la Lliga Catalana de Cambó.

El 16 de febrero se desarrollan las votaciones, en una jornada de calma general, que dieron el triunfo electoral al Frente Popular. El 3 de abril se constituye el Congreso. Azaña es elegido presidente de la República y designa a Casares para formar Gobierno en el que entraron republicanos de izquierda con apoyo socialista y comunista, con la intención de rehabilitar las medidas reformadoras de los primeros años republicanos. Con la subida al poder del Frente Popular, los religiosos marianistas vuelven a sus medidas de precaución tomadas al advenimiento de la República. Los temores no son vanos, en Cádiz las capas más bajas, cultural y económicamente, de los barrios obreros de la ciudad protagonizan una jornada de asaltos y quema de iglesias. El 8 de marzo de 1936 fue asaltado el Colegio San Felipe Neri por grupos sindicales que llegan a penetrar en el edificio y amenazan a los religiosos, saquean el mobiliario y las provisiones de la cocina, invaden los despachos y rompen y queman libros y papeles de secretaría... La bandera comunista es puesta en la fachada y desde la azotea hablan el comunista Pinto y el socialista Barberán, quienes declaran el colegio "Casa del Pueblo de todos los trabajadores". El inmueble se salvó del incendio en momentos muy tensos, hasta que la tropa salió a la calle e impuso el orden en la ciudad. Volvió la calma, pero no la seguridad.

Los religiosos vuelven a vivir en pensiones y en los antiguos escondites en casas de familias y amigos. El Inspector de los colegios marianistas, don Antonio Martínez, piensa que el Gobierno de izquierda volverá a implantar la escuela única, con suspensión de la escuela privada, para ir hacia una "sovietización de las escuelas"; y teme que en las vacaciones del verano se produzca la disolución de las Congregaciones religiosas y de toda enseñanza que no sea del Estado hasta llegar a la "revolución."

En esta situación convulsionada tuvieron lugar los exámenes de fin de curso. Al darse las vacaciones de verano, la vida de los religiosos repite sus actividades estivales, clases particulares a los alumnos suspendidos, sesiones intensas de estudio de los escolásticos y profesores para aprobar en septiembre sus cursos universitarios y los religiosos viajan para asistir a los ejercicios espirituales anuales. Al igual que el país, todos están ajenos a cualquier acontecimiento trágico. Si bien, por todas partes corren los rumores de un golpe militar; la llegada del momento decisivo de un cirujano de hierro que devuelva la paz política y el orden a la calle. Pero todo es un rumor y nadie cree en firme en la posibilidad e inminencia de un cuartelazo.

BIBLIOGRAFÍA

62 Gordejuela al P. Coulon (Asistente General de Instrucción) carta del 19, VI, 1936; revista Cincuenta Años de labor Marianista en España, 54. Los templos y conventos que ardieron en Cádiz en Arrarás, J. 1970: IV 82; y Millán, J. L. 1993. Cádiz siglo XX (1989-1979): Vol. IV 180 Cádiz: ed. Sílex; López, Á. 1993. 82 .

${ }^{63}$ Gordejuela a Schleich, 16, III, 1936 (APM: 103.049); APM: 103.119.

Hispania Sacra, LXIV, Extra I, enero-junio 2012, 149-177, e-ISSN: 1988-4265, doi: 10.3989/hs.2012.028 
Alba, V. 1961. Historia de la Segunda República española: México: libro Mex.

Andrés, M. (dir.). 1985. 50 años. Colegio Marianista. Bodas de oro: Buenos Aires: Savini Hnos. S.R.L.

Arrarás, J. 1970. Historia de la Segunda República española, (n. 1) Madrid: Editora Nacional.

Bartolomé Martínez, B. y Hernández, J. 1985. "La Federación de Amigos de la Enseñanza (FAE) como alternativa pedagógica", en Ruiz Berrio, J. (ed.), La educación en la España contemporánea. Cuestiones históricas: Madrid: Sociedad Española de Pedagogía.

Brenan, G. 1994. El laberinto español. Madrid. Globus.

Cárcel, V. 1995. Mártires españoles del siglo XX: Madrid: Biblioteca de Autores Cristianos.

Congregatio de Causis Sanctorum (Torres, E.). 1990. "Disquisitio super martyrio", en Civitatis Regalen.Canonizationis seu declarationis martyrii servorum Dei Caroli Eraña Guruceta et duorum sociorum (...) anno 1936, interfectorum. Positio super martirio: Roma: Tipografia Guerra.

Farrás, A. y Barrena, J. 1989, Marianistas en Jerez (1888/1988): Madrid: ed. SM.

Fernández Soria, J. M. 1994. "La educación en Valencia durante la República y la Guerra Civil" en Buenaventura Delgado (coord.), Historia de la Educación en España y América, III: Madrid

Gascón, A. 2002. Compañía de María (Marianistas) en España. Una contribución al desarrollo y a la evangelización (1887-1983) I, Madrid.

González, J. 1983. El colegio de San Felipe Neri: 80-81 Cádiz: Publicaciones de la Caja de Ahorros de Cádiz.

González Blasco, P e Isasa, J. 2007. "El nuevo colegio (1921-1936)”, en El Pilar, cien años de historia. 1907-2007 Madrid: Colegio Nuestra Señora del Pilar.

Gutiérrez, J. L. y Martín-Artajo, A. 1958. Doctrina Pontificia. Documentos políticos, II, Madrid: Biblioteca de Autores Cristianos.

Jarlot, G. 1984. "Guerra Mundial y Estados Totalitarios", en Historia de la Iglesia Fliche-Martin, XXVI/2: Valencia: Edicep.

Labrador, C. 1985. "Las Semanas de Estudios pedagógicos de la FAE (1932-36)", en Ruiz Berrio, J. (ed.), La educación en la España contemporánea. Cuestiones históricas: Madrid: Sociedad Española de Pedagogía.

Labrador, C. 1994. "Federación de Amigos de la Enseñanza", en Delgado, B. (coord.), Historia de la Educación en España y América, III: Madrid.

López, Á. 1993. "Cien años de Historia", en Aranda, C (dir.), Marianistas. Cien años en Cádiz: Madrid: ed. SM.

Marías, J. 1993-1994. "España ante la historia y ante sí misma (1898-1936)", en Laín. P. La edad de plata de la cultura española (1898-1936), en Jover, J. M. (dir.). Historia de España Menéndez Pidal: XXXIX/1 Madrid: Espasa-Calpe; Martínez, A. 1949. Un alma de educador. R. P. Domingo Lázaro Castro, SM (1877-1935): Burgos: Hijos de Santiago Rodríguez..

Martínez, J. 1980. Un renovador de la docencia nacional. D. Antonio Martínez García, Religioso Marianista. Fundador de Ediciones SM: 133 Madrid: ed SM.

Puelles, M. 1980. Educación e ideología en la España contemporánea: Barcelona: Labor. 
Ríos, F. y Gastaminza, F. 1987, 100 años de presencia marianista en San Sebastián. 1887-1987: Madrid: imprenta SM.

Salaverri, J. M. 2003. Domingo Lázaro (1877-1935). Un educador entre dos grandes crisis de España: Madrid: PPC. Salaverri, J. M. 2007, 75 años de presencia marianista en Valencia (1933-2008): Madrid: SPM ed. S. M.

Samaniego, M. 1977. La política educativa de la Segunda República durante el bienio azañista: Madrid: CSIC.

Tuñón de Lara, M. 1981. "La Segunda República", en Historia de España: IX Barcelona: ed. Labor. 